\title{
In Silico Molecular Dynamics Docking of Drugs to the Inhibitory Active Site of SARS-CoV-2 Protease and Their Predicted Toxicology and ADME
}

\author{
Leif E. Peterson
}

NXG Logic, LLC, Houston, Texas 77030 USA

E-mail: peterson.leif.e@gmail.com

Key words: Docking, Coronavirus, SARS-CoV-2, SARS-CoV, COVID-19, Drug discovery, Pharmaceutics, Pharmacology, Repurposing, Chemoinformatics, Toxicology, Absorption, Distribution, Metabolism, Excretion, ADME

\section{ABSTRACT}

A in silico molecular dynamics (MD) docking investigation was conducted to identify drugs (ligands) which could potentially be of interest for repurposing. We sought ligands which formed the strongest binding potential energy with the $x$-ray crystallography-based active site of the SARS-CoV-2 protease C3Lpro. A total of 11,013 ligands were obtained from DrugBank. Because of the larger size of the active site of 3CLpro, we chose ligands whose molecular weight (MW) was greater than 400 (daltons) and less than 700, which resulted in 5,920 ligands. After correction of bonds and hydrogens, there were 4,634 ligands available for docking. Docking results indicate that the top 10 investigational and experimental drugs with binding energy $(\mathrm{BE}) \leq-9$ kcal/mol were Lorecivivint, Tivantinib, Omipalisib, DrugBank B08450, SRT-2104, R-428, DrugBank B01897, Bictegravir, Ridinilazole, and Itacitinib, while the top 10 approved drugs with BE $\leq-8.2$ were Olaparib, Etoposide, Ouabain, Indinavir, Idelalisib, Trametinib, Lumacaftor, Ergotamine, Canagliflozin, and Edoxaban. There were two antiviral drugs among the top 30 hits, which were Bictegravir (investigational) and Indinavir (approved). The top 10 antivirals with BE $\leq-8.2$ were Bictegravir, Tegobuvir, Filibuvir, Saquinavir, Fostemsavir, Indinavir, Temsavir, Pimodivir, Amenamevir, and Doravirine. Interestingly, the antiviral Remdesavir ranked low among the top 30 antivirals, since its BE was a low value of $-7.5 \mathrm{kcal} / \mathrm{mol}$. In silico toxicology and ADME (absorption, distribution, metabolism, excretion) prediction indicates that only $20 \%(6 / 30)$ of the top ligands were "drug-like," and none were "lead-like," since the lower bound of MW was 400. Another interesting finding was that the investigational natural supplement Diosmin (DrugBank ID B08995), used without prescription for varicose veins, ranked 22 overall (out of 3,896 with BE $\leq-6$ ) with a strong $\mathrm{BE}=-8.8$, and formed 8 hydrogen bonds with the active site for the putative best pose. Its energy-minimized 3D structure deeply penetrated and fully covered the width of the active site's pocket. Diosmin had a lower BE than 97\% of the top 30 antiviral drugs and formed more hydrogen bonds with the active site than $93 \%$ of the top 30 antivirals. Diosmin could therefore potentially serve as a strong inhibitor of the 3CLpro protease of SARS-CoV-2 and could be investigated in human clinical trials. Since a prescription is not required for its use, it could also be explored as a self-medicating natural alternative to prescribed synthetic drugs. Lastly, the green tea component epigallocatechin gallate (DrugBank ID B12116) also had a low BE=-8.3, and formed 2 hydrogen bonds with the active site, which was a BE that was better than $70 \%$ of the top 30 antivirals. 


\section{INTRODUCTION}

The December 2019 outbreak of the novel coronavirus disease (COVID-19) in Wuhan, China eventually spread worldwide, and became an international pandemic thereafter ${ }^{[1]}$. The vector of human-to-human transmission has been confirmed to be salivary or airway droplets, contaminated hands, and surfaces ${ }^{[2]}$. Following an incubation time of 2-14 days, infection with COVID-19 coronavirus can lead to severe respiratory illness ${ }^{[3]}$. Preventive measures for minimizing the global pandemic include sheltering at home, office closures for nonessential businesses, closure of schools, universities, and child care facilities, closure of restaurants and pubs, cancellation of public sporting events, cancellation of public ceremonies, election polls and political debates, and only performing non-elective (emergency) medical procedures ${ }^{[4]}$. Medical treatment includes early diagnosis, quarantine, and supportive treatments which are essential to cure patients $s^{[5]}$. Historically, the 2003 severe acute respiratory syndrome (SARS) epidemic resulted in 8400 SARS cases and approximately 800 deaths ${ }^{[6]}$. The SARS epidemic was due to a previously unknown coronavirus (SARS-CoV), which was highly infectious and fatal. The original source of SARS-CoV was confirmed to be zoonotic, originating from an animal reservoir which includes horseshoe bats (Vespertilio ferrum-equinum) ${ }^{[7]}$ and masked palm civets (Paguma larvata) $)^{[8]}$, although the most recent genomic evidence leads to pangolins (Manis pentadactyla) ${ }^{[9]}$. The zoonotic SARS-CoV continues to be a major threat to humans, and most research groups do not exclude the possibility of reemergence of SARS.

The genome of the original SARS-CoV (2003) consists of approximately 30,000 nucleotides, and is a positivesense, single-stranded RNA sequence with 14 open reading frames (ORFs) $)^{[10]}$. There are two large ORFs for the replicase gene, which is responsible for viral RNA syntheses ${ }^{[11]}$. The remaining 12 ORFs encode the 4 structural proteins: spike, membrane, nucleocapsid and envelope; and eight accessory proteins ${ }^{[12]}$. The viral genome and its expression within the host cell undergoes extensive translational and enzymatic processing to form the 4 structural, 8 accessory and 16 nonstructural proteins ${ }^{[13]}$. The highly similar genome for COVID-19 disease is termed SARS-CoV-2 ${ }^{[14]}$, which has already been sequenced by numerous labs ${ }^{[15-19]}$. Within the proteome of SARS-CoV-2, one of the best characterized drug targets among coronaviruses is the main protease 3CLpro ${ }^{[2]}$ (or MPRO), which is responsible for processing the proteins translated from the viral RNA ${ }^{[21]}$. 3D models of $x-$ ray crystallography of novel inhibitors bound to the catalytic active site of SARS-CoV-2 protease 3CLpro were recently reported ${ }^{[22,23]}$.

Modern drug discovery includes an in silico method known as molecular dynamics (MD) docking, to reproduce chemical potentials which determine the bound conformation preference and free energy of binding between a ligand and its receptor ${ }^{[24]}$. The MD docking technique seeks to establish the optimal receptor binding pocket (pose) with a minima in the energy profile, shape, and temperature, while assuming consistency in the ligand charge distribution and protonation states for the bound and unbound forms. At each receptor pocket identified, several poses are evaluated while iterating through alternative conformations of the ligand at its rotatable covalent bonds. At present, there have been several MD docking investigations for SARS-Cov-2. Khan et al. ${ }^{[25]}$ investigated chymotrypsin-like protease inhibitors from FDA's approved antiviral drugs, and their in-house database of natural and synthetic drug-like compounds. Results indicate that 3 FDAapproved drugs (Remdesivir, Saquinavir, and Darunavir) and two natural compounds (flavone and coumarine derivatives) were identified as promising hits. Liu et al. ${ }^{[2]}$ introduced the computational technique SCAR, for discovering covalent drugs. SCAR was employed to identify possible covalent drugs (approved or clinically tested) which targeted the main protease (3CLpro) of SARS-CoV-2. They identified 11 potential hits (Itacitinib, Oberadilol, Telcagepant, Vidupiprant, Pilaralisib, Poziotinib, Fostamatinib, CL-275838, Ziprasidone, Leucal/folinic acid, ITX5061), among which at least 6 hits were exclusively enriched by the SCAR protocol. 
Lung et al. ${ }^{[27]}$ performed an MD docking study to target RdRp of SARS-CoV-2, SARS-CoV, and Middle East respiratory syndrome coronavirus (MERS-CoV), and found that Theaflavin has a lowest binding energies (BE) in the core in the catalytic pocket of RdRp in SARS-CoV-2 $(-9.11 \mathrm{kcal} / \mathrm{mol})$, SARS-CoV $(-8.03 \mathrm{kcal} / \mathrm{mol})$, and MERS-CoV (-8.26 kcal/mol). To confirm the result, they performed blind docking and discovered that Theaflavin has lower binding energy of $-8.8 \mathrm{kcal} / \mathrm{mol}$ when it docks in the catalytic pocket of SARS-CoV-2 RdRp. Lastly, Shah et al. ${ }^{[28]}$ used blind docking with SAR-CoV-2 proteins, and determined that 37 molecules were found to interact with 2 protein structures. Several of the best candidates identified were Methisazone an inhibitor of protein synthesis, CGP42112A - an angiotensin AT2 receptor agonist and, ABT450 an inhibitor of the non-structural protein 3-4A might were some of the best candidates identified.

In silico MD docking can only address the theoretical binding between a ligand and its receptor. High throughput in vitro screens, in vivo animal xenografts, as well as human clinicals trials are required before confirming that a potential inhibitory molecule can effectively be efficacious for disease therapy. Toxicology and ADME (absorption, distribution, metabolism, and excretion) prediction is another dimension of drug testing, which be accomplished in silico, in vitro, and in vivo ${ }^{[29-33]}$. It will take some time before candidates from the MD docking studies described above ${ }^{[25-28]}$ are tested and evaluated. In order to establish reproducibility and robustness of SARS-CoV-2 MD docking results from multiple studies, we undertook this investigation to report results from docking investigational, experimental, and FDA-approved drugs to the active inhibitory site of 3CLpro confirmed by x-ray crystallography (PDB: GLU7) ${ }^{[22]}$. We also performed toxicology and ADME prediction for each of the top candidates to provide a reference frame for safety related issues involved with human administration.

\section{MATERIALS AND METHODS}

Small-Molecule Ligand Library. FDA-Approved drugs, as well as investigatory and experimental compounds were obtained from DrugBank ${ }^{[34,35]}$. DrugBank (www.drugbank.ca) is a web-enabled database containing comprehensive molecular information about drugs, their mechanisms, their interactions, and their targets. Over the last 10 years, the number of investigational drugs in the database has grown by almost 300\%, and the number of drug-drug interactions has grown by nearly $600 \%$, while the number of SNP-associated drug effects has grown more than $3000 \%$. Significant improvements have been made to the quantity, quality and consistency of drug indications, drug binding data as well as drug-drug and drug-food interactions. New information in DrugBank also includes the influence of hundreds of drugs on metabolite levels (pharmacometabolomics), gene expression levels (pharmacotranscriptomics) and protein expression levels (pharmacoprotoemics). New data have also been added on the status of hundreds of new drug clinical trials and existing drug repurposing trials.

Ligand Selection and Preparation. Starting with a list of 11,013 DrugBank compounds, we filtered on molecular weight (MW), and only used drugs whose MW was within the range 100-700 daltons. We also required the existence of a SMILES string for each ligand, which when filtered resulted in 5,920 compounds. SMILES strings were converted to canonical SMILES using Open-Babel 3.0 ${ }^{[36]}(\mathrm{OB})$. The 2D canonical SMILES were first desalted, and $\mathrm{OB}$ was used to add hydrogens, and transform to a 3D. The energy of each ligand was then minimized using the Amber force field ${ }^{[37,38]}$ from within $\mathrm{OB}$, via conjugate gradients (250 iterations), updates at 1 step intervals, and a convergence criterion of 0.0001. Results were saved into 3D SDF format containing partial charges of each atom, in batches of 1000 ligands per SDF file. PyRx ${ }^{[39]}$ was then used to input SDF files to correct bonds and hydrogens, and then save in PDBQT format. Following correction of bonds and hydrogens, there were 4,634 ligands available for docking. 
Active Site (3CLpro) 3D structure. The 3D x-ray crystallography model of 3CLpro (PDB: 6LU7) ${ }^{[22]}$ bound to a novel ligand at the active site was downloaded in PDB format. PyMol was then used to select amino acid residues of 3CLpro which were within 5 angstroms $\left(\mathrm{A}^{\circ}\right.$ ) of the ligand (bound to its active site), and results were saved in PDB format. PyRx was used to merge charges and remove non-polar hydrogens, merge charges and remove lone pairs, and remove water molecules from the active site, and results were exported to PDBQT format.

Molecular Ligand-Active Site Docking. Vina ${ }^{[40]}$ was used for ligand-active site docking on Amazon AWS cloud formations with Linux high-performance compute clusters. Batches of 1000 compounds were run sequentially. A total of 10 ligand poses were assessed at the active site, and the best pose was assumed to have the lowest binding energy $(\mathrm{BE})$ in $\mathrm{kcal} / \mathrm{mol}$. BE values less than $-6 \mathrm{kcal} / \mathrm{mol}$ are considered to represent significant binding affinity.

Drug-like and Lead-like Hit Determination. Ligands that yielded a best docking pose with BE<-6 were additionally filtered using physio-chemical properties of compounds. These included lipophilicity (LogP: $\log$ of octanal-water partition coefficient) and solubility (LogS) using the SMARTS notation available from SILICOSIT ${ }^{41]}$, which were implemented in .NET. Molecular weight (MW), topological surface area (TPSA), number of hydrogen bond donors (HBD), hydrogen bond acceptors (HBA), and number of rotatable bonds (RotB) were determined using OB's .NET assembly. All compounds were kekulized and stripped of salts prior to calculation of physio-chemical properties, except for LogS solubility calculations, for which hydrogens were added. Two sets of criteria were employed for assessing suitability of ligands for lead discovery: "drug-like" and "lead-like". The drug-like hits were based on the Muegge (Bayer) criteria ${ }^{[42]}$ for which $200 \leq \mathrm{MW} \leq 600,-2 \leq \operatorname{LogP} \leq 5, \mathrm{TPSA} \leq 150$, $\mathrm{HBD} \leq 5, \mathrm{HBA} \leq 10$, and $\operatorname{Rot} B \leq 15$. Whereas the lead-like criteria were $\log P<3, M W<300, \operatorname{HBD} \leq 3, \operatorname{HBA} \leq 3$, and $\operatorname{RotB} \leq 3$.

Fathead Minnow Toxicity (FMT). The Fathead minnow is an important aquatic and terrestrial toxicity end point target, and Fathead minnow toxicity data were obtained from Cheng et al. ${ }^{[43]}$. FMT toxicity data consisted of 188 FMT- and 366 FMT+ compounds (554 total). The FMT endpoint for each compound was expressed as the concentration lethal to 50\% of the organisms (LC50) for FMT during 96h flow-through exposure tests. Cheng et al. ${ }^{[43]}$ selected a threshold value of $\mathrm{LC} 50=0.5 \mathrm{mmol} / \mathrm{L}$ to partition the data into low and high acute FMT compounds. Compounds with the value of LC50 less than $0.5 \mathrm{mmol} / \mathrm{L}$ were assigned as high acute FMT compounds, whereas others were assigned as low acute FMT compounds. The chemical name, CAS numbers, FMT test results, and SMILES strings were available in the data.

Honey Bee Toxicity (HBT). 195 pesticides or pesticide-like molecules for HBT (96 HBT-, 99 HBT+) were collected from Cheng et al. ${ }^{[43]}$, based on data from the US EPA ECOTOX database ${ }^{[44]}$. The HBT endpoint for Apis mellifera bees was expressed as the dose lethal to 50\% of the test population (LD50) during a 48h exposure test. Cheng et al. ${ }^{[43]}$ selected a threshold value of LD50=100 $\mu \mathrm{g} / \mathrm{bee}$ to designate high acute HBT compounds and low acute HBT compounds. Compounds with an LD50 below $100 \mu \mathrm{g} / \mathrm{bee}$ were coded as high acute HBT compounds, while others were coded as low acute HBT compounds. The chemical name, CAS numbers, HBT test results, and SMILES strings were available in the data.

Tetrahymena Pyriformis Toxicity (TPT). Tetrahymena pyriformis toxicity (TPT) is often used as a toxicology endpoint, and 1571 diverse TPT-tested chemicals were collected from Cheng et al. [45]. Toxicity data was expressed as the negative logarithm of $50 \%$ growth inhibitory concentration (pIGC50) values and duplicated molecules were removed. Xue et al. ${ }^{[46]}$ selected a threshold value of pIGC50=-0.5 for discriminating TPT and nonTPT compounds (compounds with pIGC50>-0.5 were assigned as TPT, otherwise as non-TPT). The entire dataset 
was then divided into 1217 TPT+ and 354 TPT- compounds. The chemical name, CAS numbers, SMILES strings and pIGC50 value of 1571 compounds were available in the data.

Human Intestinal Absorption (HIA). The original HIA dataset was collected from Shen et al. [47]. This dataset contained $n=578$ compounds with fraction absorption (\%FA) values. Shen et al. also specified a threshold value of $30 \%$ to partition compounds into HIA+ and HIA- (78 HIA- and 500 HIA+ compounds). Drugs with oral dosage formulations were considered to be HIA+ compounds. The chemical name, SMILES and class labels HIA+ and HIA- were available in the data.

Blood Brain Barrier Penetration (BBB). The BBB dataset contained $n=1593$ compounds, also obtained from Shen et al. [47], and have been categorized into BBB+ $(n=1283)$ and BBB- $(n=310)$. The chemical name, CAS numbers, BBB test results, and SMILES strings were available in the data.

Cytochrome P450 Inhibition (CYP). A large dataset containing more than 13,445 unique compounds against five major CYP isoforms, namely, 1A2, 2C9, 2C19, 2D6, and 3A4, was obtained from the PubChem AID-1851 database ${ }^{[48]}$. The assay employed for generation of these data used various human CYP P450 isozymes to measure the dealkylation of various pro-luciferin substrates to luciferin. The luciferin is then measured by luminescence after the addition of a luciferase detection reagent. Pro-luciferin substrate concentration in the assay was equal to its KM for its CYP P450 isozyme. Inhibitors and some substrates limit the production of luciferin and decrease measured luminescence. A compound was classified as a CYP inhibitor if the AC50 (the compound concentration leads to $50 \%$ of the activity of an inhibition control) value was $10 \mu \mathrm{M}$. A compound was considered as a non-inhibitor if AC50 was $>57 \mu \mathrm{M}$. Regarding samples sizes, for CYP1A2 there were 13,256 total compounds with 7,256 non-inhibitors and 6,000 inhibitors, for CYP2C9 there were 12,901 compounds with 8,782 non-inhibitors and 4,119 inhibitors, for CYP2C19 there were 13,445 molecules with 7,532 non-inhibitors and 5,913 inhibitors, for CYP2D6 there were 13,910 compounds 11,139 non-inhibitors and 2,771 inhibitors, and for CYP3A4 there were 13,017 compounds with 7,751 non-inhibitors and 5,266 inhibitors. The chemical name, CAS numbers, CYP test results, and SMILES strings were available in the data.

Chemical Fingerprints for Toxicity and ADME Predictions. One approach to computational ADME and toxicity prediction employs chemical substructure analysis of known compounds which have been tested and applies the associative rules between structure and outcome to new compounds whose substructure has been determined ${ }^{[49]}$. The traditional method for identifying chemical substructure in compounds has been based on the FP2 fingerprint, which yields the presence (absence) of various atoms, bonds, aromaticity and cyclicity, and fine structure of a compound. FP2 fingerprints are in the form of binary 1024-bit vectors which signify presence and absence of the various moieties. It is important to note that while the granularity of FP2 fingerprints is high, there is less available information related to copy number of substructure elements, so any exercise is essentially hinged to a binary yes/no dilemma.

Using the toxicity and ADME training data described above, we employed the .NET OB ${ }^{[36]}$ assembly to transform SMILES strings for each training compound into a FP2 1024-bit vector representing chemical substructures. OB yields FP2 fingerprints in the form of 2564 -byte Hex characters were translated to binary bits. Bit values were transformed from 0 to -1 , and 1 to $1+$ and appended to an analytic file with ADME or toxicity outcomes of the respective training molecule. Toxicity and ADME predictions for the selected DTP ligands were based on trained logistic regression models using 25-100 fingerprints that achieved an ROCAUC $>65 \%$ for leaveone-out cross validation. Therefore, the predictive results are crude approximations. Figure 1 illustrates the workflow employed for all ligand preparation, active site preparation, docking, drug- and lead-like filtering of docked ligands, and computational toxicology and ADME predictions. 


\section{RESULTS}

Among the 4,634 ligands employed for MD docking, 3,896 (84\%) had a BE $\leq-6 \mathrm{kcal} / \mathrm{mol}$, indicating significant binding at the active site. Table 1 lists the top 10 investigational, 10 experimental and 10 approved drugs with the best BE in the active site of 3CLpro among 3,896 ligands with a BE $\leq-6$. The rank of each ligand in terms of the least $\mathrm{BE}$ among ligands is also provided. The investigative drugs were by far the best performing candidates since they ranked 1, 2, 3, 5, 6, 8, 9, 10, 11, 12 among the docked ligands. The top 10 investigational drugs were Lorecivivint, Tivantinib, Omipalisib, SRT-2104, R-428, Bictegravir, Ridinilazole, Itacitinib, Tucatinib, and Linsitinib. Experimental drugs were the next best group among the 3,896, since the ranks of the top 10 were $4,7,14,17,23,24,26,29,32$, and 39. DrugBank ID and names among the top 10 experimental drugs were B08450, B01897, B01349, B03893, B03363, B02449, B04016, B04673, B07152, and B02006. Altogether, the investigational and experimental drugs were in the top 50 drugs among the 3,896 ligands with $B E \leq-6$. On the other hand, the top 10 approved drugs on average had lower ranks of 35, 56, 60, 91, 97, 108, 117, 154, 173, and 191. Names of approved drugs include Olaparib, Etoposide, Ouabain, Indinavir, Idelalisib, Trametinib, Lumacaftor, Ergotamine, Canagliflozin, and Edoxaban. Regarding antivirals, there were two listed in Table 1: Bictegravir (investigational) and Indinavir (approved). The ligands thionicotinamide-adenine-dinucleotide (NAD) and 3-acetylpyridine-adenine-dinucleotide had 14 and 15 hydrogen bonds at the active site, which is likely due to the two phosphates possessed by each molecular (see Figure 3, described), resulting in 18 and 17 hydrogen bond acceptors (HBA), respectively (see Figure 7, described later). Most of the approved drugs listed in Table 1 had 4-6 hydrogen bonds at the active site, which, on average, was greater than the number of hydrogen bonds for most of the investigational and experimental drugs.

\section{Top 10 Investigative Drugs}

Figure 2 illustrates the 2D molecular structure of the top 20 investigative drugs, while only the top 10 are described below with citations. Lorecivivint (Rank 1, BE=-9.3, B14883) is being investigated for osteo-arthritis, and is an inhibitor of CLK2 and DYRK1A in the Wnt pathway, enhancing chondrogenesis, chondrocyte function, and anti-inflammation. ${ }^{[50]}$ Tivantinib (Rank 2, BE=-9.3, B12200) is being studied in a randomized phase 2 network trial of tivantinib plus cetuximab versus cetuximab in patients with recurrent/metastatic head and neck squamous cell carcinoma ${ }^{[51]}$ Omipalisib (Rank 3, BE=-9.2, B12703) otherwise, known as GSK2126458, is a potent inhibitor of PI3K/mTOR, and was used in a randomized, placebo-controlled, double-blind, repeat dose escalation, experimental medicine study of subject with idiopathic pulmonary fibrosis (IPF) was conducted (NCT01725139) to test safety, tolerability, pharmacokinetics and pharmacodynamics. Results demonstrated acceptable tolerability of Omipalisib in subjects with IPF at exposures for which target engagement was confirmed both systemically and in the lungs ${ }^{[52]}$. SRT-2104:GSK-2245840 (Rank 5, BE=-9.1, B12186) otherwise known as GSK-2245840, has been studied in Type 2 diabetes ${ }^{[53]}$, neurodegenerative disease $^{[54,55]}$, psoriasis ${ }^{[56]}$, depression ${ }^{[57]}$, and ulcerative colitis ${ }^{58]}$. R-428 (Rank 6, BE=-9.1, B12411) has been studied in experimental models of breast ${ }^{[59]}$, esophogeal[60], and renal cell carcinoma ${ }^{[61]}$. Bictegravir (Rank 8, $\mathbf{B E}=-\mathbf{9 . 1}$, B11799) is an HIV-1 anti-retroviral developed by Gilead ${ }^{[62,63]}$. Ridinilazole (Rank 9, BE=-9, B15308) is a narrow-spectrum, non-absorbable antimicrobial with activity against Clostridium difficile undergoing clinical trials ${ }^{[64,65]}$. Itacitinib (Rank 10, BE=-9, B12154) is a JAK-1 inhibitor that has been studied in phase 1 and 2 trials of B-cell lymphoma and advanced solid cancers ${ }^{[6,67]}$. Tucatinib (Rank 11, BE=-9, B11652) is indicated for HER-2 positive metastatic breast cancer ${ }^{[68]}$. Linsitinib (Rank 12, BE=-9, B06075) was investigated for GI stromal, adrenocortical, breast, and prostate cancers ${ }^{[69-72]}$. 


\section{Top 10 Experimental Drugs}

Figure 3 illustrates the 2D molecular structure of the top 20 experimental drugs; the top 10 are described below with citations. n-1h-indazol-5-yl-2-(6-methylpyridin-2-yl)quinazolin-4-amine (Rank 4, BE=-9.1, B08450) is an TGF- $\beta$ type 1 receptor ALK-5 inhibitor ${ }^{[73]}$, which has been investigated in models of renal fibrosis ${ }^{[74,75]}$, and DMN-induced liver fibrosis ${ }^{[3]}$. 2-(2f-benzothiazolyl)-5-styryl-3-(4f-phthalhydrazidyl)tetrazolium chloride (Rank 7, BE=-9.1, B01897) was the first inhibitor discovered that complexed with human hematopoietic prostaglandin D synthase ${ }^{[76]}$, and as such it is an antiasthmatic ${ }^{[77]}$. Tasosartan (Rank 14, BE=-8.9, B01349) is an angiotensin II antagonist employed for antihypertension ${ }^{[78,79]}$. Thionicotinamide-adenine-dinucleotide (Rank 17, BE=-8.8, B03893) targets glyceraldehyde 3-phosphate dehydrogenase (GAPDH), and inhibition of GAPDH was shown to decrease incorporation of human proteins into HIV-1 virions ${ }^{[80]}$. 3-acetylpyridine-adeninedinucleotide (Rank 23, BE=-8.8, B03363) is a coenzyme composed of ribosylnicotinamide 5'-diphosphate coupled to adenosine 5'-phosphate by pyrophosphate linkage. It targets 4-hydroxy-tetrahydrodipicolinate reductase in E-coli, so it would have antibacterial properties. It is found widely in nature and is involved in numerous enzymatic reactions in which it serves as an electron carrier by being alternately oxidized (NAD+) and reduced (NADH) ${ }^{[81]}$. 3-(1h-indol-3-yl)-2-[4-(4-phenyl-piperidin-1-yl)-benzenesulfonylamino]-propionic acid (Rank 24, BE=-8.8, B02449) targets stromelysin-1, which degrades fibronectin, laminin, gelatins of type I, III, IV, and V; collagens III, IV, X, and IX, and cartilage proteoglycans, and activates procollagenase ${ }^{[82]}$. 2-[3(\{methyl[1-(2-naphthoyl)piperidin-4-yl]amino\}carbonyl)-2-naphthyl]-1-(1-naphthyl)-2-oxoethylphosphonic acid (Rank 26, BE=-8.7, B04016) is a novel, potent dual inhibitor of neutrophil cathepsin-G and chymase. Leukocytes release serine proteases that sustain inflammatory processes and cause disease conditions, such as asthma and chronic obstructive pulmonary disease. These findings demonstrate that it is possible to inhibit both cathepsin $G$ and chymase with a single molecule and suggest an exciting opportunity in the treatment of asthma and chronic obstructive pulmonary disease ${ }^{[83]}$. 4-[(5-chloroindol-2-yl)sulfonyl]-2-(2-methylpropyl)-1[[5-(pyridin-4-yl)pyrimidin-2-yl]carbonyl]piperazine (Rank 29, BE=-8.7, B04673) was found to inhibit and complex with coagulation factor $\mathrm{Xa}^{[84]}$, which is a vitamin $\mathrm{K}$-dependent glycoprotein that converts prothrombin to thrombin in the presence of factor Va, calcium and phospholipid during blood clotting. n-[4(5-fluoro-6-methylpyridin-2-yl)-5-quinoxalin-6-yl-1h-imidazol-2-yllacetamide (Rank 32, BE=-8.7, B07152) was found to inhibit and complex with TGF-beta receptor type-1[85], and therefore for would be employed in oncologic research. Br-coeleneterazine (Rank 39, BE=-8.7, B02006) is a luciferin, which is employed in various bioluminescence assays, especially for Ca uptake[86].

\section{Top 10 Approved Drugs}

Figure 4 shows the top 20 approved drugs, and the top 10 are described in detail as follows. Olaparib (Rank 35, BE=-8.7, B09074) is a PARP inhibitor primarily indicated for the treatment of ovarian cancer, but has been useful for pancreatic cancer, advanced solid tumors, and gallbladder cancer ${ }^{[87-92]}$. Etoposide (Rank 56, BE=-8.6, B00773) is for use in combination with other chemotherapeutic agents in the treatment of refractory testicular tumors and as first line treatment in patients with small cell lung cancer. Also used to treat other malignancies such as lymphoma, non-lymphocytic leukemia, and glioblastoma multiforme ${ }^{[93-96]}$. Ouabain (Rank 60, BE=-8.6, B01092) is indicated for treatment of atrial fibrillation and flutter and heart failure ${ }^{[97-102]}$, and has been investigated in oncology ${ }^{[93,103]}$. Indinavir (Rank 91, BE=-8.5, B00224) is an antiretroviral drug for the treatment of HIV infection ${ }^{[104-106]}$. Idelalisib (Rank 97, BE=-8.4, B09054) is indicated in the treatment of chronic lymphocytic leukemia (CLL), relapsed follicular B-cell non-Hodgkin lymphoma (FL), and relapsed small lymphocytic lymphoma (SLL), and has been of interest for renal cell cancer ${ }^{[107-110]}$. Trametinib (Rank 108, BE=8.4, B08911) is indicated for the treatment of unresectable or metastatic melanoma [107], advanced rectal[111], breast $^{[112]}$, biliary ${ }^{[113]}$, colorectal, non-small cell lung, and pancreatic cancer ${ }^{[114]}$. Lumacaftor (Rank 117, BE=-8.4, 
B09280) is indicated for the treatment of cystic fibrosis (CF) in patients age 6 years and older who are homozygous for the F508del mutation in the CFTR gene ${ }^{[15-117]}$. Ergotamine (Rank 154, BE=-8.3, B00696) is for use as therapy to abort or prevent vascular headache, e.g., migraine, migraine variants, or so called "histaminic cephalalgia"[118-120]. Canagliflozin (Rank 173, BE=-8.2, B08907) is used in conjunction with diet and exercise to increase glycemic control in adults diagnosed with type 2 diabetes mellitus major cardiovascular events (myocardial infarction, stroke, or death due to a cardiovascular cause) in patients with type 2 diabetes, as well as hospitalization for heart failure in patients with type 2 diabetes ${ }^{[121,122]}$. Edoxaban (Rank 191, BE=-8.2, B09075) is indicated for reducing the risk of stroke and systemic embolism (SE) in patients with nonvalvular atrial fibrillation (NVAF) ${ }^{[123-126]}$.

Figure 5 shows the putative binding poses of the Table 1 candidate hits. Each image shows the structure of the substrate binding pocket of the active site of the SARS-CoV-2 3CLpro protease (PDB ID: 6LU7). The white surface in each image represents the surface of the active site of 3CLpro that would be traced out by water molecules in contact with the protein at all possible positions. The inhibitors (ligands) are shown in molecular stick format. As one can notice, many of these ligands in their energy-minimized conformation bind deeply at the active site of 3CLpro, as well as span the distance of the entire outside distance.

Lastly, we noticed that the investigational natural supplement Diosmin (DrugBank ID B08995), used without prescription for varicose veins, had an overall rank of 22 among all docked ligands with a strong BE=-8.8 and formed 8 hydrogen bonds with the active site for the putative best pose. The 2D molecular structure of Diosmin is shown in Figure 2 - which shows the top 20 docked investigational ligands. A series of docking images for Diosmin bound to the active site of 3CLpro are shown in Figure 6, which illustrates that Diosmin covers the entire width and penetrates deeply into the active site with hydrogens throughout its molecular backbone. When compared with the top 30 antiviral drugs, only Fostemsavir and Raltegravir had 8 hydrogen bonds for their putative best pose at the active site, but their BE values of -8.5 and -8.1 were greater (worse) than the -8.8 for Diosmin. Accordingly, Diosmin's BE was lower than $97 \%$ of the top 30 antiviral drug and formed more hydrogen bonds with the active site than $93 \%$ of the top 30 antivirals. This indicates that Diosmin could potentially serve as a strong inhibitor of 3CLpro and could be investigated in human clinical trials. Since a prescription is not required for its use, it could also be explored as a self-medicating natural alternative to prescribed synthetic drugs for inhibiting the 3CLpro protease of SARS-CoV-2. Finally, the green tea component epigallocatechin gallate (DrugBank ID B12116) also had a low BE=-8.3, and formed 2 hydrogen bonds with the active site, which was a BE that was better than $70 \%$ of the top 30 antivirals.

\section{Toxicology and ADME}

Toxicology and ADME prediction (Figure 7) indicate that 6 of the 30 ligands (20\%) in Table 1 were drug-like, and none were lead-like, due the MW exceeding 300. The majority of ligands that were not drug-like had values for $\log P, M W$, LogS, number of hydrogen bond donors (HBD), number of hydrogen bond acceptors (HBA) out of range for drug-like characteristics. The first drug-like candidate was the antiviral Bictegravir, which has a lower MW of 449.4 daltons and only 4 rotatable bonds. Its probabilities for HBT and TPT were greater than 95\%, and the probability of CYP inhibition was above 50\% for several enzymes. The structural alerts for Bictegravir were not any worse than the majority of the drugs listed. The remaining 5 drug-like ligands were Itacitinib, Olaparib, Ergotamine, Canagliflozin, and Edoxaban. These 6 drug-like candidates could possibly surpass any off-label usage concerns for treating COVID-19 by regulatory agencies, since 4 are already approved (Olaparib, Ergotamine, Canagliflozin, Edoxaban), and the remaining 2 (Bictegravir, Itacitinib) are investigational and are being used in human clinical trials. 


\section{Comparison of Antivirals}

Table 2 lists the top 30 antivirals that were docked with the active site of the 3CLpro protease. The top 10 antivirals yielding the lowest BE were Bictegravir, Tegobuvir, Filibuvir, Saquinavir, Fostemsavir, Indinavir, Temsavir, Pimodivir, Amenamevir, and Doravirine. Interestingly, Remdesavir was among a set of 5 antivirals that ranked 12 with a much worse BE of $-7.5 \mathrm{kcal} / \mathrm{mol}$. Overall, the top antivirals were the investigational Bictegravir (BE=-9.1) and the approved Indinavir $(\mathrm{BE}=-8.5)$. Figure 8 shows the putative binding poses of the antivirals at the active site of the 3CLpro protease. Many of the antivirals bind deeply at the active site of 3CLpro, as well as span the distance of the entire outside distance. However, some do not, like Remdesavir, which only partially cover the entire width of the active site pocket.

\section{DISCUSSION}

COVID-19 disease is highly transmissible and has been shown to result in acute respiratory failure in patients who are elderly, immune-compromised, and have pre-existing conditions. Two important hallmarks of COVID19 are the rapidity in the onset of symptoms and the magnitude of resources required for intensive care for patients. Together, these factors directly and indirectly support the need for prevention of pandemics on a global scale which may occur in the future.

Our approach employed two in silico levels of computation, one that involved MD docking on high-performance compute clusters, and another based on toxicology and ADME predictions. MD docking results indicate that many ligands yielded high-quality BE's which were less than the assumed threshold of $-6 \mathrm{kcal} / \mathrm{mol}$, for which significant binding is assumed. Specifically, MD docking was considered significant for $10 \%$ of the ligands employed. It is important to realize that our approach to MD docking was targeted and hypothesis-driven, in that we focused on ligand binding within in the known inhibitory active site based on x-ray crystallographic data and not on a 3D model of a consensus sequence based on Blasting or alignment. We also did employ a data-driven approach that is similar to "blind" docking, in which BE's are sought for ligands binding in any pockets found on the surface of a 3D proteomic model.

We also predicted toxicology and ADME for ligand with significant binding to the active site. The predictions indicate that $23 \%$ of the top 30 ligands were drug-like, and only one was lead-like. Experimental laboratory in vitro and in vivo toxicology and ADME studies using animal models of SARS-CoV-2 could be used to support the findings that were reported. The clinical value of our results is established by the potential for repurposing drugs for treating COVID-19, which could prove useful in animal studies, transgenics, and xenograft models, etc., to confirm results of this study and the other docking studies which have been recently been reported. Due to the expediency in finding optimal treatments for the global COVID-19 disease pandemic, initiation of human trials for compassionate use with one or more of the compounds identified in this investigation could also be undertaken, given that several of the compounds are now used in human trials.

There were several differences between our study and the other docking reports which were recently published. Liu et al. ${ }^{[26]}$ employed targeted docking of the active sit of 3CLpro, but used an additional enrichment protocol called SCAR (steric clashes alleviating receptors), and none of their top compounds were listed among our top 30. Lung et al. ${ }^{[27]}$ used a ligand library that consisted of 83 traditional Chinese medicinals, and in addition to SARS-CoV-2 employed SARS-Cov and MERS proteins. Shah et al. [28] employed a ligand library of 61 antivirals, and reported that several of the compounds had significant binding with more than two "protein structures" of COVID-19, but did not report the specific antivirals. Khan et al. ${ }^{[25]}$ used the 3CLpro protein, and reported that 
three antivirals (Remdesivir, Saquinavir and Darunavir) and two natural compounds (flavone and coumarine) had significant binding. In light of what has been reported thus far, the only antivirals in our top 30 hit list were Bictegraivir and Indinavir, although there were other antivirals whose BE with the active site of 3CLpro was less than $-6 \mathrm{kcal} / \mathrm{mol}$.

Lastly, we did not comparatively assess numerous MD docking and toxicological/ADME prediction techniques for their computational efficiency, scalability, or differences. We also did not evaluate differences between targeted active site and blind docking, or bootstrapping effects on results.

\section{FUNDING}

Funding for research was based on research and development support from NXG Logic, LLC.

\section{CONFLICTS OF INTEREST}

None declared.

\section{REFERENCES}

1. Zhai P, Ding Y, Wu X, Long J, Zhong Y, Li Y. The epidemiology, diagnosis and treatment of COVID-19. Int J Antimicrob Agents. 2020:105955. Epub 2020/04/03. doi: 10.1016/j.ijantimicag.2020.105955. PubMed PMID: 32234468; PMCID: PMC7138178.

2. Park M, Cook AR, Lim JT, Sun Y, Dickens BL. A Systematic Review of COVID-19 Epidemiology Based on Current Evidence. J Clin Med. 2020;9(4). Epub 2020/04/05. doi: 10.3390/jcm9040967. PubMed PMID: 32244365.

3. Ahn DG, Shin HJ, Kim MH, Lee S, Kim HS, Myoung J, Kim BT, Kim SJ. Current Status of Epidemiology, Diagnosis, Therapeutics, and Vaccines for Novel Coronavirus Disease 2019 (COVID-19). J Microbiol Biotechnol. 2020;30(3):313-24. Epub 2020/04/03. doi: 10.4014/jmb.2003.03011. PubMed PMID: 32238757.

4. Pan A, Liu L, Wang C, Guo H, Hao X, Wang Q, Huang J, He N, Yu H, Lin X, Wei S, Wu T. Association of Public Health Interventions With the Epidemiology of the COVID-19 Outbreak in Wuhan, China. JAMA. 2020. Epub 2020/04/11. doi: 10.1001/jama.2020.6130. PubMed PMID: 32275295.

5. Huang X, Wei F, Hu L, Wen L, Chen K. Epidemiology and Clinical Characteristics of COVID-19. Arch Iran Med. 2020;23(4):268-71. Epub 2020/04/10. doi: 10.34172/aim.2020.09. PubMed PMID: 32271601.

6. Ziebuhr J. Molecular biology of severe acute respiratory syndrome coronavirus. Curr Opin Microbiol. 2004;7(4):412-9. Epub 2004/09/11. doi: 10.1016/j.mib.2004.06.007. PubMed PMID: 15358261; PMCID: PMC7108451.

7. Zhou P, Yang XL, Wang XG, Hu B, Zhang L, Zhang W, Si HR, Zhu Y, Li B, Huang CL, Chen HD, Chen J, Luo $Y$, Guo H, Jiang RD, Liu MQ, Chen Y, Shen XR, Wang X, Zheng XS, Zhao K, Chen QJ, Deng F, Liu LL, Yan B, Zhan FX, Wang YY, Xiao GF, Shi ZL. A pneumonia outbreak associated with a new coronavirus of probable bat origin. Nature. 2020;579(7798):270-3. Epub 2020/02/06. doi: 10.1038/s41586020-2012-7. PubMed PMID: 32015507; PMCID: PMC7095418.

8. Guan Y, Zheng BJ, He YQ, Liu XL, Zhuang ZX, Cheung CL, Luo SW, Li PH, Zhang LJ, Guan YJ, Butt KM, Wong KL, Chan KW, Lim W, Shortridge KF, Yuen KY, Peiris JS, Poon LL. Isolation and characterization of viruses related to the SARS coronavirus from animals in southern China. Science. 2003;302(5643):276-8. Epub 2003/09/06. doi: 10.1126/science.1087139. PubMed PMID: 12958366. 
9. Zhang T, Wu Q, Zhang Z. Probable Pangolin Origin of SARS-CoV-2 Associated with the COVID-19 Outbreak. Curr Biol. 2020;30(7):1346-51 e2. Epub 2020/03/21. doi: 10.1016/j.cub.2020.03.022. PubMed PMID: 32197085.

10. Khan S, Siddique R, Shereen MA, Ali A, Liu J, Bai Q, Bashir N, Xue M. The emergence of a novel coronavirus (SARS-CoV-2), their biology and therapeutic options. J Clin Microbiol. 2020. Epub 2020/03/13. doi: 10.1128/JCM.00187-20. PubMed PMID: 32161092.

11. Satija N, Lal SK. The molecular biology of SARS coronavirus. Ann N Y Acad Sci. 2007;1102:26-38. Epub 2007/05/02. doi: 10.1196/annals.1408.002. PubMed PMID: 17470909.

12. Lu IL, Mahindroo N, Liang PH, Peng YH, Kuo CJ, Tsai KC, Hsieh HP, Chao YS, Wu SY. Structure-based drug design and structural biology study of novel nonpeptide inhibitors of severe acute respiratory syndrome coronavirus main protease. J Med Chem. 2006;49(17):5154-61. Epub 2006/08/18. doi: 10.1021/jm060207o. PubMed PMID: 16913704.

13. Ghosh AK, Xi K, Johnson ME, Baker SC, Mesecar AD. Progress in Anti-SARS Coronavirus Chemistry, Biology and Chemotherapy. Annu Rep Med Chem. 2007;41:183-96. Epub 2007/02/01. doi: 10.1016/S00657743(06)41011-3. PubMed PMID: 19649165; PMCID: PMC2718771.

14. Colson P, Lagier JC, Baudoin JP, Bou Khalil J, La Scola B, Raoult D. Ultrarapid diagnosis, microscope imaging, genome sequencing, and culture isolation of SARS-CoV-2. Eur J Clin Microbiol Infect Dis. 2020. Epub 2020/04/10. doi: 10.1007/s10096-020-03869-w. PubMed PMID: 32270412.

15. Yip CC, Ho CC, Chan JF, To KK, Chan HS, Wong SC, Leung KH, Fung AY, Ng AC, Zou Z, Tam AR, Chung TW, Chan KH, Hung IF, Cheng VC, Tsang OT, Tsui SKW, Yuen KY. Development of a Novel, Genome Subtraction-Derived, SARS-CoV-2-Specific COVID-19-nsp2 Real-Time RT-PCR Assay and Its Evaluation Using Clinical Specimens. Int J Mol Sci. 2020;21(7). Epub 2020/04/12. doi: 10.3390/ijms21072574. PubMed PMID: 32276333.

16. Yadav PD, Potdar VA, Choudhary ML, Nyayanit DA, Agrawal M, Jadhav SM, Majumdar TD, Shete-Aich A, Basu A, Abraham P, Cherian SS. Full-genome sequences of the first two SARS-CoV-2 viruses from India. Indian J Med Res. 2020. Epub 2020/04/04. doi: 10.4103/ijmr.IJMR_663_20. PubMed PMID: 32242873.

17. Stefanelli P, Faggioni G, Lo Presti A, Fiore S, Marchi A, Benedetti E, Fabiani C, Anselmo A, Ciammaruconi A, Fortunato A, De Santis R, Fillo S, Capobianchi MR, Gismondo MR, Ciervo A, Rezza G, Castrucci MR, Lista F, On Behalf Of Iss Covid-Study G. Whole genome and phylogenetic analysis of two SARS-CoV-2 strains isolated in Italy in January and February 2020: additional clues on multiple introductions and further circulation in Europe. Euro Surveill. 2020;25(13). Epub 2020/04/09. doi: 10.2807/1560-7917.ES.2020.25.13.2000305. PubMed PMID: 32265007; PMCID: PMC7140597.

18. Sah R, Rodriguez-Morales AJ, Jha R, Chu DKW, Gu H, Peiris M, Bastola A, Lal BK, Ojha HC, Rabaan AA, Zambrano LI, Costello A, Morita K, Pandey BD, Poon LLM. Complete Genome Sequence of a 2019 Novel Coronavirus (SARS-CoV-2) Strain Isolated in Nepal. Microbiol Resour Announc. 2020;9(11). Epub 2020/03/14. doi: 10.1128/MRA.00169-20. PubMed PMID: 32165386; PMCID: PMC7067954.

19. Licastro D, Rajasekharan S, Dal Monego S, Segat L, D'Agaro P, Marcello A, Regione FVGLGoC. Isolation and full-length genome characterization of SARS-CoV-2 from COVID-19 cases in Northern Italy. J Virol. 2020. Epub 2020/04/03. doi: 10.1128/JVI.00543-20. PubMed PMID: 32238585.

20. Anand K, Ziebuhr J, Wadhwani P, Mesters JR, Hilgenfeld R. Coronavirus main proteinase (3CLpro) structure: basis for design of anti-SARS drugs. Science. 2003;300(5626):1763-7. Epub 2003/05/15. doi: 10.1126/science.1085658. PubMed PMID: 12746549.

21. Hilgenfeld R. From SARS to MERS: crystallographic studies on coronaviral proteases enable antiviral drug design. FEBS J. 2014;281(18):4085-96. Epub 2014/07/22. doi: 10.1111/febs.12936. PubMed PMID: 25039866.

22. Jin Z, Du, X., Xu, Y., Deng, Y., Liu, M., Zhao, Y., Zhang, B., Li, X., Zhang, L., Peng, C., Duan, Y., Yu, J., Wang, L., Yang, K., Liu, F., Jiang, R., Yang, X., You, T., Liu, X., Yang, X., Bai, F., Liu, H., Liu, X., Guddat, 
L., Xu, W., Xiao, G., Qin, C., Shi, Z., Jiang, H., Rao, Z., Yang, H. Structure of Mpro from COVID-19 virus and discovery of its inhibitors. Nature. 2020. doi: https://doi.org/10.1038/s41586-020-2223-y.

23. Zhang L, Lin D, Sun X, Curth U, Drosten C, Sauerhering L, Becker S, Rox K, Hilgenfeld R. Crystal structure of SARS-CoV-2 main protease provides a basis for design of improved alpha-ketoamide inhibitors. Science. 2020. Epub 2020/03/22. doi: 10.1126/science.abb3405. PubMed PMID: 32198291.

24. Gilson MK, Given JA, Bush BL, McCammon JA. The statistical-thermodynamic basis for computation of binding affinities: a critical review. Biophys J. 1997;72(3):1047-69. Epub 1997/03/01. doi: 10.1016/S00063495(97)78756-3. PubMed PMID: 9138555; PMCID: PMC1184492.

25. Khan SA, Zia K, Ashraf S, Uddin R, Ul-Haq Z. Identification of Chymotrypsin-like Protease Inhibitors of SARS-CoV-2 Via Integrated Computational Approach. J Biomol Struct Dyn. 2020:1-13. Epub 2020/04/03. doi: 10.1080/07391102.2020.1751298. PubMed PMID: 32238094.

26. Liu S, Zheng Q, Wang Z. Potential covalent drugs targeting the main protease of the SARS-CoV-2 coronavirus. Bioinformatics. 2020. Epub 2020/04/03. doi: 10.1093/bioinformatics/btaa224. PubMed PMID: 32239142.

27. Lung J, Lin YS, Yang YH, Chou YL, Shu LH, Cheng YC, Liu HT, Wu CY. The potential chemical structure of anti-SARS-CoV-2 RNA-dependent RNA polymerase. J Med Virol. 2020. Epub 2020/03/14. doi: 10.1002/jmv.25761. PubMed PMID: 32167173.

28. Shah B, Modi P, Sagar SR. In silico studies on therapeutic agents for COVID-19: Drug repurposing approach. Life Sci. 2020:117652. Epub 2020/04/13. doi: 10.1016/j.lfs.2020.117652. PubMed PMID: 32278693.

29. Fielden MR, Matthews JB, Fertuck KC, Halgren RG, Zacharewski TR. In silico approaches to mechanistic and predictive toxicology: an introduction to bioinformatics for toxicologists. Crit Rev Toxicol. 2002;32(2):67-112. Epub 2002/04/16. doi: 10.1080/20024091064183. PubMed PMID: 11951993.

30. Ekins S. In silico approaches to predicting drug metabolism, toxicology and beyond. Biochem Soc Trans. 2003;31(Pt 3):611-4. Epub 2003/05/30. doi: 10.1042/. PubMed PMID: 12773166.

31. Helma C. In silico predictive toxicology: the state-of-the-art and strategies to predict human health effects. Curr Opin Drug Discov Devel. 2005;8(1):27-31. Epub 2005/02/01. PubMed PMID: 15679168.

32. Holtzman S. In silico toxicology. Ann N Y Acad Sci. 2000;919:68-74. Epub 2000/11/18. PubMed PMID: 11083098.

33. Cronin MT. In silico toxicology challenges for pharmaceuticals: complacency or controversy? Altern Lab Anim. 2009;37(5):453-6. Epub 2009/12/19. PubMed PMID: 20017576.

34. Wishart DS, Knox C, Guo AC, Shrivastava S, Hassanali M, Stothard P, Chang Z, Woolsey J. DrugBank: a comprehensive resource for in silico drug discovery and exploration. Nucleic Acids Res.

2006;34(Database issue):D668-72. Epub 2005/12/31. doi: 10.1093/nar/gkj067. PubMed PMID: 16381955; PMCID: PMC1347430.

35. Wishart DS, Feunang YD, Guo AC, Lo EJ, Marcu A, Grant JR, Sajed T, Johnson D, Li C, Sayeeda Z, Assempour N, Iynkkaran I, Liu Y, Maciejewski A, Gale N, Wilson A, Chin L, Cummings R, Le D, Pon A, Knox C, Wilson M. DrugBank 5.0: a major update to the DrugBank database for 2018. Nucleic Acids Res. 2018;46(D1):D1074-D82. Epub 2017/11/11. doi: 10.1093/nar/gkx1037. PubMed PMID: 29126136; PMCID: PMC5753335.

36. O'Boyle NM, Banck M, James CA, Morley C, Vandermeersch T, Hutchison GR. Open Babel: An open chemical toolbox. J Cheminform. 2011;3:33. Epub 2011/10/11. doi: 10.1186/1758-2946-3-33. PubMed PMID: 21982300; PMCID: PMC3198950.

37. Kini RM, Evans HJ. Molecular modeling of proteins: a strategy for energy minimization by molecular mechanics in the AMBER force field. J Biomol Struct Dyn. 1991;9(3):475-88. Epub 1991/12/01. doi: 10.1080/07391102.1991.10507930. PubMed PMID: 1687724.

38. Wang J, Wolf RM, Caldwell JW, Kollman PA, Case DA. Development and testing of a general amber force field. J Comput Chem. 2004;25(9):1157-74. Epub 2004/04/30. doi: 10.1002/jcc.20035. PubMed PMID: 15116359. 
39. Dallakyan S, Olson AJ. Small-molecule library screening by docking with PyRx. Methods Mol Biol. 2015;1263:243-50. Epub 2015/01/27. doi: 10.1007/978-1-4939-2269-7_19. PubMed PMID: 25618350.

40. Trott $\mathrm{O}$, Olson AJ. AutoDock Vina: improving the speed and accuracy of docking with a new scoring function, efficient optimization, and multithreading. J Comput Chem. 2010;31(2):455-61. Epub 2009/06/06. doi: 10.1002/jcc.21334. PubMed PMID: 19499576; PMCID: PMC3041641.

41. De Winter H. SILICOS-IT Filter-It. http://silicos-itbes3-website-eu-west-1amazonawscom/ (Accession date, 11 July, 2018). 2018.

42. Muegge I, Heald SL, Brittelli D. Simple selection criteria for drug-like chemical matter. J Med Chem. 2001;44(12):1841-6. Epub 2001/06/01. PubMed PMID: 11384230.

43. Cheng F, Shen, J., Li,W., Lee, P.W., Tang, Y. . In silico prediction of terrestrial and aquatic toxicities for organic chemicals. Chin J Pestic Sci. 2010;12:477-88.

44. EPA. US EPA ECOTOX Database. https://cfpub.epa.gov/ecotox/ (Accession date, 11 July, 2018). 2018.

45. Cheng F, Shen, J., Li, W., Yu., Y., Liu, G., Lee, P.W., Tang, Y. In silico prediction of Tetrahymena Pyriformis toxicity for diverse industrial chemicals with substructure pattern recognition and machine learning methods. Chemosphere. 2011;82(1):1636-43.

46. Xue Y, Li H, Ung CY, Yap CW, Chen YZ. Classification of a diverse set of Tetrahymena pyriformis toxicity chemical compounds from molecular descriptors by statistical learning methods. Chem Res Toxicol. 2006;19(8):1030-9. Epub 2006/08/22. doi: 10.1021/tx0600550. PubMed PMID: 16918241.

47. Shen J, Cheng F, Xu Y, Li W, Tang Y. Estimation of ADME properties with substructure pattern recognition. J Chem Inf Model. 2010;50(6):1034-41. Epub 2010/06/29. doi: 10.1021/ci100104j. PubMed PMID: 20578727.

48. NCBI. NCBI PubChem Database AID-1851. Cytochrome panel assay with activity outcomes. https://pubchem.ncbi.nlm.nih.gov/bioassay/1851/ (Accession date, 11 July, 2018). 2018.

49. Zaretzki J, Boehm KM, Swamidass SJ. Improved Prediction of CYP-Mediated Metabolism with Chemical Fingerprints. J Chem Inf Model. 2015;55(5):972-82. Epub 2015/04/15. doi: 10.1021/ci5005652. PubMed PMID: 25871613.

50. Deshmukh V, O'Green AL, Bossard C, Seo T, Lamangan L, Ibanez M, Ghias A, Lai C, Do L, Cho S, Cahiwat J, Chiu K, Pedraza M, Anderson S, Harris R, Dellamary L, Kc S, Barroga C, Melchior B, Tam B, Kennedy S, Tambiah J, Hood J, Yazici Y. Modulation of the Wnt pathway through inhibition of CLK2 and DYRK1A by lorecivivint as a novel, potentially disease-modifying approach for knee osteoarthritis treatment. Osteoarthritis Cartilage. 2019;27(9):1347-60. Epub 2019/05/28. doi: 10.1016/j.joca.2019.05.006. PubMed PMID: 31132406.

51. Kochanny SE, Worden FP, Adkins DR, Lim DW, Bauman JE, Wagner SA, Brisson RJ, Karrison TG, Stadler WM, Vokes EE, Seiwert TY. A randomized phase 2 network trial of tivantinib plus cetuximab versus cetuximab in patients with recurrent/metastatic head and neck squamous cell carcinoma. Cancer. 2020. Epub 2020/02/20. doi: 10.1002/cncr.32762. PubMed PMID: 32073648.

52. Lukey PT, Harrison SA, Yang S, Man Y, Holman BF, Rashidnasab A, Azzopardi G, Grayer M, Simpson JK, Bareille P, Paul L, Woodcock HV, Toshner R, Saunders P, Molyneaux PL, Thielemans K, Wilson FJ, Mercer PF, Chambers RC, Groves AM, Fahy WA, Marshall RP, Maher TM. A randomised, placebocontrolled study of omipalisib (PI3K/mTOR) in idiopathic pulmonary fibrosis. Eur Respir J. 2019;53(3). Epub 2019/02/16. doi: 10.1183/13993003.01992-2018. PubMed PMID: 30765508.

53. Libri V, Brown AP, Gambarota G, Haddad J, Shields GS, Dawes H, Pinato DJ, Hoffman E, Elliot PJ, Vlasuk GP, Jacobson E, Wilkins MR, Matthews PM. A pilot randomized, placebo controlled, double blind phase I trial of the novel SIRT1 activator SRT2104 in elderly volunteers. PLoS One. 2012;7(12):e51395. Epub 2013/01/04. doi: 10.1371/journal.pone.0051395. PubMed PMID: 23284689; PMCID: PMC3527451.

54. Kitaoka Y, Sase K, Tsukahara C, Fujita N, Tokuda N, Kogo J, Takagi H. Axonal protection by a small molecule SIRT1 activator, SRT2104, with alteration of autophagy in TNF-induced optic nerve 
degeneration. Jpn J Ophthalmol. 2020. Epub 2020/03/12. doi: 10.1007/s10384-020-00731-6. PubMed PMID: 32157485.

55. Jiang M, Zheng J, Peng Q, Hou Z, Zhang J, Mori S, Ellis JL, Vlasuk GP, Fries H, Suri V, Duan W. Sirtuin 1 activator SRT2104 protects Huntington's disease mice. Ann Clin Transl Neurol. 2014;1(12):1047-52. Epub 2015/01/13. doi: 10.1002/acn3.135. PubMed PMID: 25574479; PMCID: PMC4284130.

56. Krueger JG, Suarez-Farinas M, Cueto I, Khacherian A, Matheson R, Parish LC, Leonardi C, Shortino D, Gupta A, Haddad J, Vlasuk GP, Jacobson EW. A Randomized, Placebo-Controlled Study of SRT2104, a SIRT1 Activator, in Patients with Moderate to Severe Psoriasis. PLoS One. 2015;10(11):e0142081. Epub 2015/11/12. doi: 10.1371/journal.pone.0142081. PubMed PMID: 26556603; PMCID: PMC4640558.

57. Duan CM, Zhang JR, Wan TF, Wang Y, Chen HS, Liu L. SRT2104 attenuates chronic unpredictable mild stress-induced depressive-like behaviors and imbalance between microglial M1 and M2 phenotypes in the mice. Behav Brain Res. 2020;378:112296. Epub 2019/10/17. doi: 10.1016/j.bbr.2019.112296. PubMed PMID: 31618623.

58. Sands BE, Joshi S, Haddad J, Freudenberg JM, Oommen DE, Hoffmann E, McCallum SW, Jacobson E. Assessing Colonic Exposure, Safety, and Clinical Activity of SRT2104, a Novel Oral SIRT1 Activator, in Patients with Mild to Moderate Ulcerative Colitis. Inflamm Bowel Dis. 2016;22(3):607-14. Epub 2015/11/26. doi: 10.1097/MIB.0000000000000597. PubMed PMID: 26595549; PMCID: PMC4885523.

59. Holland SJ, Pan A, Franci C, Hu Y, Chang B, Li W, Duan M, Torneros A, Yu J, Heckrodt TJ, Zhang J, Ding P, Apatira A, Chua J, Brandt R, Pine P, Goff D, Singh R, Payan DG, Hitoshi Y. R428, a selective small molecule inhibitor of Axl kinase, blocks tumor spread and prolongs survival in models of metastatic breast cancer. Cancer Res. 2010;70(4):1544-54. Epub 2010/02/11. doi: 10.1158/0008-5472.CAN-09-2997. PubMed PMID: 20145120.

60. Yang PW, Liu YC, Chang YH, Lin CC, Huang PM, Hua KT, Lee JM, Hsieh MS. Cabozantinib (XL184) and R428 (BGB324) Inhibit the Growth of Esophageal Squamous Cell Carcinoma (ESCC). Front Oncol. 2019;9:1138. Epub 2019/11/30. doi: 10.3389/fonc.2019.01138. PubMed PMID: 31781483; PMCID: PMC6851194.

61. Woo SM, Min KJ, Seo SU, Kim S, Kubatka P, Park JW, Kwon TK. Axl Inhibitor R428 Enhances TRAILMediated Apoptosis Through Downregulation of c-FLIP and Survivin Expression in Renal Carcinoma. Int J Mol Sci. 2019;20(13). Epub 2019/07/05. doi: 10.3390/ijms20133253. PubMed PMID: 31269715; PMCID: PMC6651098.

62. Gouget H, Noe G, Barrail-Tran A, Furlan V. UPLC-MS/MS method for the simultaneous quantification of bictegravir and 13 others antiretroviral drugs plus cobicistat and ritonavir boosters in human plasma. J Pharm Biomed Anal. 2020;181:113057. Epub 2020/01/22. doi: 10.1016/j.jpba.2019.113057. PubMed PMID: 31962247.

63. Courlet P, Alves Saldanha S, Cavassini M, Marzolini C, Choong E, Csajka C, Gunthard HF, Andre P, Buclin T, Desfontaine V, Decosterd LA. Development and validation of a multiplex UHPLC-MS/MS assay with stable isotopic internal standards for the monitoring of the plasma concentrations of the antiretroviral drugs bictegravir, cabotegravir, doravirine, and rilpivirine in people living with HIV. J Mass Spectrom. 2020:e4506. Epub 2020/03/12. doi: 10.1002/jms.4506. PubMed PMID: 32160389.

64. Vickers RJ, Tillotson G, Goldstein EJ, Citron DM, Garey KW, Wilcox MH. Ridinilazole: a novel therapy for Clostridium difficile infection. Int J Antimicrob Agents. 2016;48(2):137-43. Epub 2016/06/11. doi: 10.1016/j.ijantimicag.2016.04.026. PubMed PMID: 27283730.

65. Cho JC, Crotty MP, Pardo J. Ridinilazole: a novel antimicrobial for Clostridium difficile infection. Ann Gastroenterol. 2019;32(2):134-40. Epub 2019/03/07. doi: 10.20524/aog.2018.0336. PubMed PMID: 30837785; PMCID: PMC6394264.

66. Phillips TJ, Forero-Torres A, Sher T, Diefenbach CS, Johnston P, Talpaz M, Pulini J, Zhou L, Scherle P, Chen X, Barr PM. Phase 1 study of the PI3Kdelta inhibitor INCB040093 +/- JAK1 inhibitor itacitinib in 
relapsed/refractory B-cell lymphoma. Blood. 2018;132(3):293-306. Epub 2018/04/27. doi: 10.1182/blood2017-10-812701. PubMed PMID: 29695516; PMCID: PMC6107856.

67. Beatty GL, Shahda S, Beck T, Uppal N, Cohen SJ, Donehower R, Gabayan AE, Assad A, Switzky J, Zhen $\mathrm{H}$, Von Hoff DD. A Phase Ib/II Study of the JAK1 Inhibitor, Itacitinib, plus nab-Paclitaxel and Gemcitabine in Advanced Solid Tumors. Oncologist. 2019;24(1):14-e0. Epub 2018/08/18. doi: 10.1634/theoncologist.2017-0665. PubMed PMID: 30115734; PMCID: PMC6324630 article.

68. Murthy RK, Loi S, Okines A, Paplomata E, Hamilton E, Hurvitz SA, Lin NU, Borges V, Abramson V, Anders C, Bedard PL, Oliveira M, Jakobsen E, Bachelot T, Shachar SS, Muller V, Braga S, Duhoux FP, Greil R, Cameron D, Carey LA, Curigliano G, Gelmon K, Hortobagyi G, Krop I, Loibl S, Pegram M, Slamon D, Palanca-Wessels MC, Walker L, Feng W, Winer EP. Tucatinib, Trastuzumab, and Capecitabine for HER2-Positive Metastatic Breast Cancer. N Engl J Med. 2020;382(7):597-609. Epub 2019/12/12. doi: 10.1056/NEJMoa1914609. PubMed PMID: 31825569.

69. von Mehren M, George S, Heinrich MC, Schuetze SM, Yap JT, Yu JQ, Abbott A, Litwin S, Crowley J, Belinsky M, Janeway KA, Hornick JL, Flieder DB, Chugh R, Rink L, Van den Abbeele AD. Linsitinib (OSI-906) for the Treatment of Adult and Pediatric Wild-Type Gastrointestinal Stromal Tumors, a SARC Phase II Study. Clin Cancer Res. 2020;26(8):1837-45. Epub 2019/12/04. doi: 10.1158/1078-0432.CCR-191069. PubMed PMID: 31792037.

70. Li W, Wang Z, Wang L, He X, Wang G, Liu H, Guo F, Wang Z, Chen G. Effectiveness of inhibitor rapamycin, saracatinib, linsitinib and JNJ-38877605 against human prostate cancer cells. Int J Clin Exp Med. 2015;8(4):6563-7. Epub 2015/07/02. PubMed PMID: 26131286; PMCID: PMC4483836.

71. Kruger DT, Alexi X, Opdam M, Schuurman K, Voorwerk L, Sanders J, van der Noort V, Boven E, Zwart W, Linn SC. IGF-1R pathway activation as putative biomarker for linsitinib therapy to revert tamoxifen resistance in ER-positive breast cancer. Int J Cancer. 2020;146(8):2348-59. Epub 2019/09/07. doi: 10.1002/ijc.32668. PubMed PMID: 31490549; PMCID: PMC7065127.

72. Fassnacht M, Berruti A, Baudin E, Demeure MJ, Gilbert J, Haak H, Kroiss M, Quinn DI, Hesseltine E, Ronchi CL, Terzolo M, Choueiri TK, Poondru S, Fleege T, Rorig R, Chen J, Stephens AW, Worden F, Hammer GD. Linsitinib (OSI-906) versus placebo for patients with locally advanced or metastatic adrenocortical carcinoma: a double-blind, randomised, phase 3 study. Lancet Oncol. 2015;16(4):426-35. Epub 2015/03/22. doi: 10.1016/S1470-2045(15)70081-1. PubMed PMID: 25795408.

73. Gellibert F, Fouchet MH, Nguyen VL, Wang R, Krysa G, de Gouville AC, Huet S, Dodic N. Design of novel quinazoline derivatives and related analogues as potent and selective ALK5 inhibitors. Bioorg Med Chem Lett. 2009;19(8):2277-81. Epub 2009/03/17. doi: 10.1016/j.bmcl.2009.02.087. PubMed PMID: 19285388.

74. Yim HE, Kim MK, Bae IS, Kim JH, Choi BM, Yoo KH, Hong YS, Lee JW. AT1 antagonist modulates activin-like kinase 5 and TGF-beta receptor II in the developing kidney. Pediatr Nephrol. 2006;21(10):1377-88. Epub 2006/08/10. doi: 10.1007/s00467-006-0197-0. PubMed PMID: 16897002.

75. Moon JA, Kim HT, Cho IS, Sheen YY, Kim DK. IN-1130, a novel transforming growth factor-beta type I receptor kinase (ALK5) inhibitor, suppresses renal fibrosis in obstructive nephropathy. Kidney Int. 2006;70(7):1234-43. Epub 2006/08/25. doi: 10.1038/sj.ki.5001775. PubMed PMID: 16929250.

76. Inoue T, Okano Y, Kado Y, Aritake K, Irikura D, Uodome N, Okazaki N, Kinugasa S, Shishitani H, Matsumura H, Kai Y, Urade Y. First determination of the inhibitor complex structure of human hematopoietic prostaglandin D synthase. J Biochem. 2004;135(3):279-83. Epub 2004/04/29. doi: 10.1093/jb/mvh033. PubMed PMID: 15113825.

77. Carron CP, Trujillo JI, Olson KL, Huang W, Hamper BC, Dice T, Neal BE, Pelc MJ, Day JE, Rohrer DC, Kiefer JR, Moon JB, Schweitzer BA, Blake TD, Turner SR, Woerndle R, Case BL, Bono CP, Dilworth VM, Funckes-Shippy CL, Hood BL, Jerome GM, Kornmeier CM, Radabaugh MR, Williams ML, Davies MS, Wegner CD, Welsch DJ, Abraham WM, Warren CJ, Dowty ME, Hua F, Zutshi A, Yang JZ, Thorarensen A. Discovery of an Oral Potent Selective Inhibitor of Hematopoietic Prostaglandin D Synthase (HPGDS). 
ACS Med Chem Lett. 2010;1(2):59-63. Epub 2010/05/13. doi: 10.1021/m1900025z. PubMed PMID: 24900177; PMCID: PMC4007851.

78. Maillard MP, Rossat J, Brunner HR, Burnier M. Tasosartan, enoltasosartan, and angiotensin II receptor blockade: the confounding role of protein binding. J Pharmacol Exp Ther. 2000;295(2):649-54. Epub 2000/10/25. PubMed PMID: 11046101.

79. Elokdah HM, Friedrichs GS, Chai SY, Harrison BL, Primeau J, Chlenov M, Crandall DL. Novel human metabolites of the angiotensin-II antagonist tasosartan and their pharmacological effects. Bioorg Med Chem Lett. 2002;12(15):1967-71. Epub 2002/07/13. doi: 10.1016/s0960-894x(02)00303-7. PubMed PMID: 12113820.

80. Kishimoto N, Onitsuka A, Kido K, Takamune N, Shoji S, Misumi S. Glyceraldehyde 3-phosphate dehydrogenase negatively regulates human immunodeficiency virus type 1 infection. Retrovirology. 2012;9:107. Epub 2012/12/15. doi: 10.1186/1742-4690-9-107. PubMed PMID: 23237566; PMCID: PMC3531276.

81. Reddy SG, Scapin G, Blanchard JS. Interaction of pyridine nucleotide substrates with Escherichia coli dihydrodipicolinate reductase: thermodynamic and structural analysis of binary complexes.

Biochemistry. 1996;35(41):13294-302. Epub 1996/10/15. doi: 10.1021/bi9615809. PubMed PMID: 8873595.

82. Pavlovsky AG, Williams MG, Ye QZ, Ortwine DF, Purchase CF, 2nd, White AD, Dhanaraj V, Roth BD, Johnson LL, Hupe D, Humblet C, Blundell TL. X-ray structure of human stromelysin catalytic domain complexed with nonpeptide inhibitors: implications for inhibitor selectivity. Protein Sci. 1999;8(7):145562. Epub 1999/07/28. doi: 10.1110/ps.8.7.1455. PubMed PMID: 10422833; PMCID: PMC2144373.

83. de Garavilla L, Greco MN, Sukumar N, Chen ZW, Pineda AO, Mathews FS, Di Cera E, Giardino EC, Wells GI, Haertlein BJ, Kauffman JA, Corcoran TW, Derian CK, Eckardt AJ, Damiano BP, AndradeGordon P, Maryanoff BE. A novel, potent dual inhibitor of the leukocyte proteases cathepsin G and chymase: molecular mechanisms and anti-inflammatory activity in vivo. J Biol Chem. 2005;280(18):180017. Epub 2005/03/03. doi: 10.1074/jbc.M501302200. PubMed PMID: 15741158.

84. Komoriya S, Haginoya N, Kobayashi S, Nagata T, Mochizuki A, Suzuki M, Yoshino T, Horino H, Nagahara T, Suzuki M, Isobe Y, Furugoori T. Design, synthesis, and biological activity of non-basic compounds as factor Xa inhibitors: SAR study of S1 and aryl binding sites. Bioorg Med Chem. 2005;13(12):3927-54. Epub 2005/05/25. doi: 10.1016/j.bmc.2005.04.006. PubMed PMID: 15911309.

85. Bonafoux D, Chuaqui C, Boriack-Sjodin PA, Fitch C, Hankins G, Josiah S, Black C, Hetu G, Ling L, Lee WC. 2-Aminoimidazoles inhibitors of TGF-beta receptor 1. Bioorg Med Chem Lett. 2009;19(3):912-6. Epub 2009/01/13. doi: 10.1016/j.bmcl.2008.11.119. PubMed PMID: 19135364.

86. Toma S, Chong KT, Nakagawa A, Teranishi K, Inouye S, Shimomura O. The crystal structures of semisynthetic aequorins. Protein Sci. 2005;14(2):409-16. Epub 2005/01/06. doi: 10.1110/ps.041067805. PubMed PMID: 15632284; PMCID: PMC2253417.

87. Griguolo G, Dieci MV, Miglietta F, Guarneri V, Conte P. Olaparib for advanced breast cancer. Future Oncol. 2020. Epub 2020/04/07. doi: 10.2217/fon-2019-0689. PubMed PMID: 32249603.

88. Zhang W, Shi J, Li R, Han Z, Li L, Li G, Yang B, Yin Q, Wang Y, Ke Y, Li Q. Effectiveness of Olaparib Treatment in a Patient with Gallbladder Cancer with an ATM-Inactivating Mutation. Oncologist. 2020. Epub 2020/02/12. doi: 10.1634/theoncologist.2019-0498. PubMed PMID: 32045060.

89. Rolfo C, Isambert N, Italiano A, Molife LR, Schellens JHM, Blay JY, Decaens T, Kristeleit R, Rosmorduc O, Demlova R, Lee MA, Ravaud A, Kopeckova K, Learoyd M, Bannister W, Locker G, de Vos-Geelen J. Pharmacokinetics and safety of olaparib in patients with advanced solid tumours and mild or moderate hepatic impairment. Br J Clin Pharmacol. 2020. Epub 2020/04/01. doi: 10.1111/bcp.14283. PubMed PMID: 32227355.

90. Randall M, Burgess K, Buckingham L, Usha L. Exceptional Response to Olaparib in a Patient With Recurrent Ovarian Cancer and an Entire BRCA1 Germline Gene Deletion. J Natl Compr Canc Netw. 2020;18(3):223-8. Epub 2020/03/07. doi: 10.6004/jnccn.2019.7378. PubMed PMID: 32135515. 
91. Banerjee S, Davidson R, McLaurin K, Sawyer W, Long GH. Adverse events in women switching from olaparib capsules to tablets: retrospective observational study of US claims data. Future Oncol. 2020;16(11):643-54. Epub 2020/04/02. doi: 10.2217/fon-2020-0142. PubMed PMID: 32228096.

92. Aschenbrenner DS. Olaparib Approved for Metastatic Pancreatic Cancer. Am J Nurs. 2020;120(4):22-3. Epub 2020/03/29. doi: 10.1097/01.NAJ.0000660008.32418.6c. PubMed PMID: 32218041.

93. Nandakumar N, Gopinath P, Gopas J, Muraleedharan KM. Benzisothiazolone Derivatives Exhibit Cytotoxicity in Hodgkin's Lymphoma Cells through NF-B Inhibition and are Synergistic with Doxorubicin and Etoposide. Anticancer Agents Med Chem. 2020. Epub 2020/02/14. doi:

10.2174/1871520620666200213103513. PubMed PMID: 32053083.

94. McHugh DJ, Funt SA, Silber D, Knezevic A, Patil S, O'Donnell D, Tsai S, Reuter VE, Sheinfeld J, Carver BS, Motzer RJ, Bajorin DF, Bosl GJ, Feldman DR. Adjuvant Chemotherapy With Etoposide Plus Cisplatin for Patients With Pathologic Stage II Nonseminomatous Germ Cell Tumors. J Clin Oncol. 2020;38(12):1332-7. Epub 2020/02/29. doi: 10.1200/JCO.19.02712. PubMed PMID: 32109195.

95. Martinez N, Miyasaki A, Roh L, Koole W, Fernandez KS. A pediatric desensitization protocol for etoposide. Am J Health Syst Pharm. 2020;77(4):277-81. Epub 2020/02/08. doi: 10.1093/ajhp/zxz311. PubMed PMID: 32031209.

96. Marconi G, Talami A, Abbenante MC, Sartor C, Parisi S, Nanni J, Bertamini L, Ragaini S, Olivi M, de Polo S, Cristiano G, Fontana MC, Bochicchio MT, Ottaviani E, Arpinati M, Sessa M, Baldazzi C, Caso L, Testoni N, Baccarani M, Bonifazi F, Martinelli G, Paolini S, Cavo M, Papayannidis C, Curti A. MEC (mitoxantrone, etoposide, and cytarabine) induces complete remission and is an effective bridge to transplant in acute myeloid leukemia. Eur J Haematol. 2020. Epub 2020/03/08. doi: 10.1111/ejh.13406. PubMed PMID: 32145118.

97. Yusuf SM, Gans JH. In vitro metabolism of atrial and ventricular myocardium: effect of ouabain. Arch Int Pharmacodyn Ther. 1966;160(1):188-95. Epub 1966/03/01. PubMed PMID: 5960118.

98. Wongcharoen W, Chen YC, Chen YJ, Lin CI, Chen SA. Effects of aging and ouabain on left atrial arrhythmogenicity. J Cardiovasc Electrophysiol. 2007;18(5):526-31. Epub 2007/03/09. doi: 10.1111/j.15408167.2007.00781.x. PubMed PMID: 17343722.

99. Schott A. Suppression of ouabain-induced atrial arrhythmias by carotid sinus stimulation. Br J Pharmacol Chemother. 1961;17:12-20. Epub 1961/08/01. doi: 10.1111/j.1476-5381.1961.tb01099.x. PubMed PMID: 13748516; PMCID: PMC1482075.

100. Higgs LM, Glancy DL, O'Brien KP, Epstein SE. Effects of ouabain on the left ventricular response to atrial pacing in patients with angina pectoris. Am J Cardiol. 1971;28(1):17-24. Epub 1971/07/01. doi: 10.1016/0002-9149(71)90029-4. PubMed PMID: 5092149.

101. Govier WC. The Mechanism of the Atrial Refractory Period Change Produced by Ouabain. J Pharmacol Exp Ther. 1965;148:100-5. Epub 1965/04/01. PubMed PMID: 14279172.

102. Shen JJ, Zhan YC, Li HY, Wang Z. Ouabain impairs cancer metabolism and activates AMPK-Src signaling pathway in human cancer cell lines. Acta Pharmacol Sin. 2020;41(1):110-8. Epub 2019/09/14. doi: 10.1038/s41401-019-0290-0. PubMed PMID: 31515527.

103. Rupaimoole R, Yoon B, Zhang WC, Adams BD, Slack FJ. A High-Throughput Small Molecule Screen Identifies Ouabain as Synergistic with miR-34a in Killing Lung Cancer Cells. iScience. 2020;23(2):100878. Epub 2020/02/18. doi: 10.1016/j.isci.2020.100878. PubMed PMID: 32062455; PMCID: PMC7031322.

104. Wang RG, Zhang HX, Zheng QC. Revealing the binding and drug resistance mechanism of amprenavir, indinavir, ritonavir, and nelfinavir complexed with HIV-1 protease due to double mutations G48T/L89M by molecular dynamics simulations and free energy analyses. Phys Chem Chem Phys. 2020;22(8):4464-80. Epub 2020/02/15. doi: 10.1039/c9cp06657h. PubMed PMID: 32057044.

105. Pollak EB, Parmar M. Indinavir. StatPearls. Treasure Island (FL)2020.

106. Knudsen AD, Krebs-Demmer L, Bjorge NID, Elming MB, Gelpi M, Sigvardsen PE, Lebech AM, Fuchs A, Ku HJ, Kober L, Lundgren J, Nordestgaard BG, Kofoed KF, Nielsen SD. Pericardial adipose tissue 
volume is independently associated with HIV status and prior use of stavudine, didanosine or indinavir. J Infect Dis. 2020. Epub 2020/02/07. doi: 10.1093/infdis/jiaa057. PubMed PMID: 32027374.

107. Ghia P, Coutre SE, Cheson BD, Barrientos JC, Hillmen P, Pettitt AR, Zelenetz AD, Shreay S, Hallek M, Furman RR. Impact of idelalisib on health-related quality of life in patients with relapsed chronic lymphocytic leukemia in a phase 3 randomized trial. Haematologica. 2020. Epub 2020/02/15. doi: 10.3324/haematol.2019.238808. PubMed PMID: 32054652.

108. Gabrielli G, Broccoli A, Pellegrini C, Argnani L, Cavo M, Zinzani PL. Idelalisib as a Bridge to Allogeneic Transplantation in Relapsed/Refractory Lymphoma With Renal Cancer: A Case Report. Clin Lymphoma Myeloma Leuk. 2020;20(1):e15-e7. Epub 2019/11/13. doi: 10.1016/j.clml.2019.10.008. PubMed PMID: 31711891.

109. Danilov AV, Herbaux C, Walter HS, Hillmen P, Rule SA, Kio EA, Karlin L, Dyer MJ, Mitra S, Yi PC, Humeniuk R, Huang X, Zhou Z, Bhargava P, Jurgensmeier JM, Fegan CD. Phase 1b Study of Tirabrutinib in Combination With Idelalisib or Entospletinib in Previously Treated Chronic Lymphocytic Leukemia. Clin Cancer Res. 2020. Epub 2020/03/12. doi: 10.1158/1078-0432.CCR-19-3504. PubMed PMID: 32156743.

110. Bleckmann A, Dierks S, Schildhaus HU, Hellige N, Bacher U, Trumper L, Wulf G. Treatment response to idelalisib in a patient with immunodeficiency-associated Burkitt lymphoma harboring a PIK3CA H1047R mutation. Ann Hematol. 2020. Epub 2020/03/21. doi: 10.1007/s00277-020-03974-y. PubMed PMID: 32193631.

111. Wu C, Williams TM, Robb R, Webb A, Wei L, Chen W, Mikhail S, Ciombor KK, Cardin DB, Timmers C, Krishna SG, Arnold M, Harzman A, Abdel-Misih S, Roychowdhury S, Bekaii-Saab T, Wuthrick E. Phase I Trial of Trametinib with Neoadjuvant Chemoradiation in Patients with Locally Advanced Rectal Cancer. Clin Cancer Res. 2020. Epub 2020/04/08. doi: 10.1158/1078-0432.CCR-19-4193. PubMed PMID: 32253228.

112. Seo T, Noguchi E, Yoshida M, Mori T, Tanioka M, Sudo K, Shimomura A, Yonemori K, Fujiwara Y, Tamura K. Response to Dabrafenib and Trametinib of a Patient with Metaplastic Breast Carcinoma Harboring a BRAF V600E Mutation. Case Rep Oncol Med. 2020;2020:2518383. Epub 2020/03/25. doi: 10.1155/2020/2518383. PubMed PMID: 32206360; PMCID: PMC7079252 publication of this article.

113. Kim RD, McDonough S, El-Khoueiry AB, Bekaii-Saab TS, Stein SM, Sahai V, Keogh GP, Kim EJ, Baron AD, Siegel AB, Barzi A, Guthrie KA, Javle M, Hochster H. Randomised phase II trial (SWOG S1310) of single agent MEK inhibitor trametinib Versus 5-fluorouracil or capecitabine in refractory advanced biliary cancer. Eur J Cancer. 2020;130:219-27. Epub 2020/04/03. doi: 10.1016/j.ejca.2020.01.026. PubMed PMID: 32234665.

114. Huijberts S, van Geel R, van Brummelen EMJ, Opdam FL, Marchetti S, Steeghs N, Pulleman S, Thijssen B, Rosing H, Monkhorst K, Huitema ADR, Beijnen JH, Bernards R, Schellens JHM. Phase I study of lapatinib plus trametinib in patients with KRAS-mutant colorectal, non-small cell lung, and pancreatic cancer. Cancer Chemother Pharmacol. 2020. Epub 2020/04/11. doi: 10.1007/s00280-020-04066-4. PubMed PMID: 32274564.

115. Misgault B, Chatron E, Reynaud Q, Touzet S, Abely M, Melly L, Dominique S, Troussier F, Ronsin-Pradel O, Gerardin M, Mankikian J, Cosson L, Chiron R, Bounyar L, Porzio M, Durieu I, Weiss L, Kessler R, Kessler L. Effect of one-year lumacaftor-ivacaftor treatment on glucose tolerance abnormalities in cystic fibrosis patients. J Cyst Fibros. 2020. Epub 2020/03/24. doi: 10.1016/j.jcf.2020.03.002. PubMed PMID: 32201160.

116. Favia M, Gallo C, Guerra L, De Venuto D, Diana A, Polizzi AM, Montemurro P, Mariggio MA, Leonetti G, Manca A, Casavola V, Conese M. Treatment of Cystic Fibrosis Patients Homozygous for F508del with Lumacaftor-Ivacaftor (Orkambi((R))) Restores Defective CFTR Channel Function in Circulating Mononuclear Cells. Int J Mol Sci. 2020;21(7). Epub 2020/04/05. doi: 10.3390/ijms21072398. PubMed PMID: 32244302.

117. Aalbers BL, de Winter-de Groot KM, Arets HGM, Hofland RW, de Kiviet AC, van Oirschot-van de Ven MMM, Kruijswijk MA, Schotman S, Michel S, van der Ent CK, Heijerman HGM. Clinical effect of 
lumacaftor/ivacaftor in F508del homozygous CF patients with FEV1 >/=90\% predicted at baseline. J Cyst Fibros. 2020. Epub 2020/01/12. doi: 10.1016/j.jcf.2019.12.015. PubMed PMID: 31924546.

118. Perrin VL. Clinical pharmacokinetics of ergotamine in migraine and cluster headache. Clin Pharmacokinet. 1985;10(4):334-52. Epub 1985/07/01. doi: 10.2165/00003088-198510040-00004. PubMed PMID: 3899452.

119. Packard RC. Case report: changes in migraine headache pattern following sudden increase in ergotamine intake. Postgrad Med. 1977;61(5):255, 7. Epub 1977/05/01. doi: 10.1080/00325481.1977.11712202. PubMed PMID: 854491.

120. Goodell H, Ostfeld AM, Pichler E, Wolff HG. Studies on headache; central versus peripheral action of ergotamine tartrate and its relevance to the therapy of migraine headache. AMA Arch Neurol Psychiatry. 1956;76(6):571-7. Epub 1956/12/01. PubMed PMID: 13371972.

121. Davies MJ, Merton K, Vijapurkar U, Yee J, Qiu R. Efficacy and safety of canagliflozin in patients with type 2 diabetes based on history of cardiovascular disease or cardiovascular risk factors: a post hoc analysis of pooled data. Cardiovasc Diabetol. 2017;16(1):40. Epub 2017/03/23. doi: 10.1186/s12933-0170517-7. PubMed PMID: 28327140; PMCID: PMC5361783.

122. Budoff MJ, Wilding JPH. Effects of canagliflozin on cardiovascular risk factors in patients with type 2 diabetes mellitus. Int J Clin Pract. 2017;71(5). Epub 2017/05/17. doi: 10.1111/ijcp.12948. PubMed PMID: 28508457; PMCID: PMC5488174.

123. Zelniker TA, Ruff CT, Wiviott SD, Blanc JJ, Cappato R, Nordio F, Mercuri MF, Lanz H, Antman EM, Braunwald E, Giugliano RP. Edoxaban in atrial fibrillation patients with established coronary artery disease: Insights from ENGAGE AF-TIMI 48. Eur Heart J Acute Cardiovasc Care. 2019;8(2):176-85. Epub 2018/07/25. doi: 10.1177/2048872618790561. PubMed PMID: 30039978.

124. Tsujino Y, Sakamoto T, Kinoshita K, Nakatani Y, Yamaguchi Y, Kataoka N, Nishida K, Kinugawa K. Edoxaban suppresses the progression of atrial fibrosis and atrial fibrillation in a canine congestive heart failure model. Heart Vessels. 2019;34(8):1381-8. Epub 2019/03/16. doi: 10.1007/s00380-019-01377-2. PubMed PMID: 30874892.

125. Shan X, Liu Z, Wulasihan M, Ma S. Edoxaban improves atrial fibrillation and thromboembolism through regulation of the Wnt-beta-induced PI3K/ATK-activated protein C system. Exp Ther Med. 2019;17(5):3509-17. Epub 2019/04/17. doi: 10.3892/etm.2019.7379. PubMed PMID: 30988731; PMCID: PMC6447810.

126. Cervantes CE, Merino JL, Barrios V. Edoxaban for the prevention of stroke in patients with atrial fibrillation. Expert Rev Cardiovasc Ther. 2019;17(4):319-30. Epub 2019/03/23. doi:

10.1080/14779072.2019.1598263. PubMed PMID: 30897988. 
Table 1. List of top 10 investigational, experimental, and approved drugs having the best binding energy (BE) at the active site of 3CLpro protease of SARS-CoV-2 proteome. Ranks listed are among the 3,896 ligands whose BE $\leq-6 \mathrm{kcal} / \mathrm{mol}$. Number of hydrogen $(\mathrm{H})$ bonds represent all polar contacts at all angstrom lengths.

\begin{tabular}{|c|c|c|c|c|c|c|}
\hline $\begin{array}{l}\text { DrugBank } \\
\text { ID }\end{array}$ & Rank & Name/structural formula & $\mathrm{BE}(\mathrm{kcal} / \mathrm{mol})$ & $\begin{array}{l}\text { Number } \\
\text { H-bonds }\end{array}$ & Usage & Status \\
\hline B14883 & 1 & Lorecivivint & -9.3 & 2 & Osteoarthritis & Investigational \\
\hline B12200 & 2 & Tivantinib & -9.3 & 3 & Oncology & Investigational \\
\hline B12703 & 3 & Omipalisib & -9.2 & 3 & Pulm. fibrosis & Investigational \\
\hline B08450 & 4 & N-1h-indazol-5-yl-2-(6-methylpyridin-2-yl)quinazolin-4-amine & -9.1 & 2 & Renal fibrosis & Experimental \\
\hline B12186 & 5 & SRT-2104 (GSK-2245840) & -9.1 & 2 & Dyslipidemia & Investigational \\
\hline B12411 & 6 & $\mathrm{R}-428$ & -9.1 & 1 & Oncology & Investigational \\
\hline B01897 & 7 & 2-(2f-benzothiazolyl)-5-styryl-3-(4f-phthalhydrazidyl)tetrazolium_chloride & -9.1 & 2 & Antiasthmatic & Experimental \\
\hline B11799 & 8 & Bictegravir & -9.1 & 4 & Antiviral(HIV1) & Investigational \\
\hline B15308 & 9 & Ridinilazole & -9 & 2 & Antimicrobial & Investigational \\
\hline B12154 & 10 & Itacitinib & -9 & 2 & Oncology & Investigational \\
\hline B11652 & 11 & Tucatinib & -9 & 2 & Oncology & Investigational \\
\hline B06075 & 12 & Linsitinib & -9 & 1 & Oncology & Investigational \\
\hline B01349 & 14 & Tasosartan & -8.9 & 3 & Hypertension & Experimental \\
\hline B03893 & 17 & Thionicotinamide-adenine-dinucleotide (NAD) & -8.8 & 14 & $\begin{array}{l}\text { Antiviral(in } \\
\text { vitro) }\end{array}$ & Experimental \\
\hline B03363 & 23 & 3-acetylpyridine-adenine-dinucleotide & -8.8 & 15 & Antibacterial & Experimental \\
\hline B02449 & 24 & 3-(1h-indol-3-yl)-2-[4-(4-phenyl-piperidin-1-yl)-benzenesulfonylamino]-propionic acid & -8.8 & 2 & Osteoarthritis & Experimental \\
\hline B04016 & 26 & $\begin{array}{l}\text { 2-[3-(\{methyl[1-(2-naphthoyl)piperidin-4-yl]amino\}carbonyl)-2-naphthyl]-1-(1-naphthyl)-2- } \\
\text { oxoethylphosphonic acid }\end{array}$ & -8.7 & 1 & Asthma/COPD & Experimental \\
\hline B04673 & 29 & $\begin{array}{l}\text { 4-[(5-chloroindol-2-yl)sulfonyl]-2-(2-methylpropyl)-1-[[5-(pyridin-4-yl)pyrimidin-2- } \\
\text { yl]carbonyl]piperazine }\end{array}$ & -8.7 & 2 & Anticoagulant & Experimental \\
\hline B07152 & 32 & n-[4-(5-fluoro-6-methylpyridin-2-yl)-5-quinoxalin-6-yl-1h-imidazol-2-yl]acetamide & -8.7 & 3 & Oncology & Experimental \\
\hline B09074 & 35 & Olaparib & -8.7 & 4 & Oncology & Approved \\
\hline B02006 & 39 & Br-coeleneterazine & -8.7 & 4 & Luciferins & Experimental \\
\hline B00773 & 56 & Etoposide & -8.6 & 6 & Oncology & Approved \\
\hline B01092 & 60 & Ouabain & -8.6 & 5 & Atrial fib/flutter & Approved \\
\hline B00224 & 91 & Indinavir & -8.5 & 6 & Antiviral(HIV1) & Approved \\
\hline B09054 & 97 & Idelalisib & -8.4 & 6 & Oncology & Approved \\
\hline B08911 & 108 & Trametinib & -8.4 & 1 & Oncology & Approved \\
\hline B09280 & 117 & Lumacaftor & -8.4 & 5 & $\mathrm{CF}$ & Approved \\
\hline B00696 & 154 & Ergotamine & -8.3 & 2 & Migraine & Approved \\
\hline B08907 & 173 & Canagliflozin & -8.2 & 3 & Type 2 DM & Approved \\
\hline B09075 & 191 & Edoxaban & -8.2 & 4 & Atrial fib. & Approved \\
\hline
\end{tabular}


Table 2. Top 30 Antiviral drugs and their binding energy (BE) at the active inhibitory site of 3CLpro protease of SARS-Cov-2 proteome. Rank sets represent groups of antivirals having the same BE. Number of hydrogen $(\mathrm{H})$ bonds represent all polar contacts at all angstrom lengths.

\begin{tabular}{|c|c|c|c|c|c|}
\hline Rank set & DrugBank ID & Antiviral & $\begin{array}{c}\text { BE } \\
\text { (kcal/mol) } \\
\end{array}$ & $\begin{array}{l}\text { Number } \\
\text { H-bonds }\end{array}$ & Status \\
\hline 1 & B11799 & Bictegravir & -9.1 & 4 & Investigational \\
\hline \multirow[t]{3}{*}{2} & B11852 & Tegobuvir & -8.6 & 1 & Investigational \\
\hline & B11878 & Filibuvir & -8.6 & 7 & Investigational \\
\hline & B01232 & Saquinavir & -8.6 & 4 & Investigational \\
\hline \multirow[t]{2}{*}{3} & B11796 & Fostemsavir & -8.5 & 8 & Investigational \\
\hline & B00224 & Indinavir & -8.5 & 6 & Approved \\
\hline \multirow[t]{3}{*}{4} & B14675 & Temsavir & -8.4 & 3 & Investigational \\
\hline & B14974 & Pimodivir & -8.4 & 6 & Investigational \\
\hline & B11701 & Amenamevir & -8.4 & 3 & Investigational \\
\hline 5 & B12301 & Doravirine & -8.2 & 2 & Investigational \\
\hline 6 & B06817 & Raltegravir & -8.1 & 8 & Approved \\
\hline \multirow[t]{5}{*}{7} & B15145 & Ziresovir & -8.0 & 1 & Investigational \\
\hline & B06414 & Etravirine & -8.0 & 2 & Approved \\
\hline & B12225 & Beclabuvir & -8.0 & 1 & Investigational \\
\hline & B12051 & Setrobuvir & -8.0 & 2 & Investigational \\
\hline & B11751 & Cabotegravir & -8.0 & 4 & Investigational \\
\hline \multirow[t]{2}{*}{8} & B08639 & Dapivirine & -7.9 & 0 & Investigational \\
\hline & B08864 & Rilpivirine & -7.9 & 4 & Approved \\
\hline 9 & B12178 & Telinavir & -7.8 & 6 & Investigational \\
\hline \multirow[t]{3}{*}{10} & B14850 & Deleobuvir & $\begin{array}{l}-7.7 \\
\end{array}$ & 4 & Investigational \\
\hline & B08930 & Dolutegravir & -7.7 & 3 & Approved \\
\hline & B14929 & Elsulfavirine & -7.7 & 0 & Investigational \\
\hline 11 & B00220 & Nelfinavir & -7.6 & 4 & Approved \\
\hline \multirow[t]{5}{*}{12} & B13997 & Baloxavir Marboxil & -7.5 & 5 & Investigational \\
\hline & B15550 & Pradefovir & -7.5 & 2 & Investigational \\
\hline & B00932 & Tipranavir & -7.5 & 3 & Investigational \\
\hline & B14761 & Remdesivir & -7.5 & 4 & Experimental \\
\hline & B04835 & Maraviroc & -7.5 & 2 & Investigational \\
\hline 13 & B00701 & Amprenavir & -7.4 & 5 & Investigational \\
\hline 14 & B06166 & Fosdevirine & -7.3 & 4 & Investigational \\
\hline
\end{tabular}




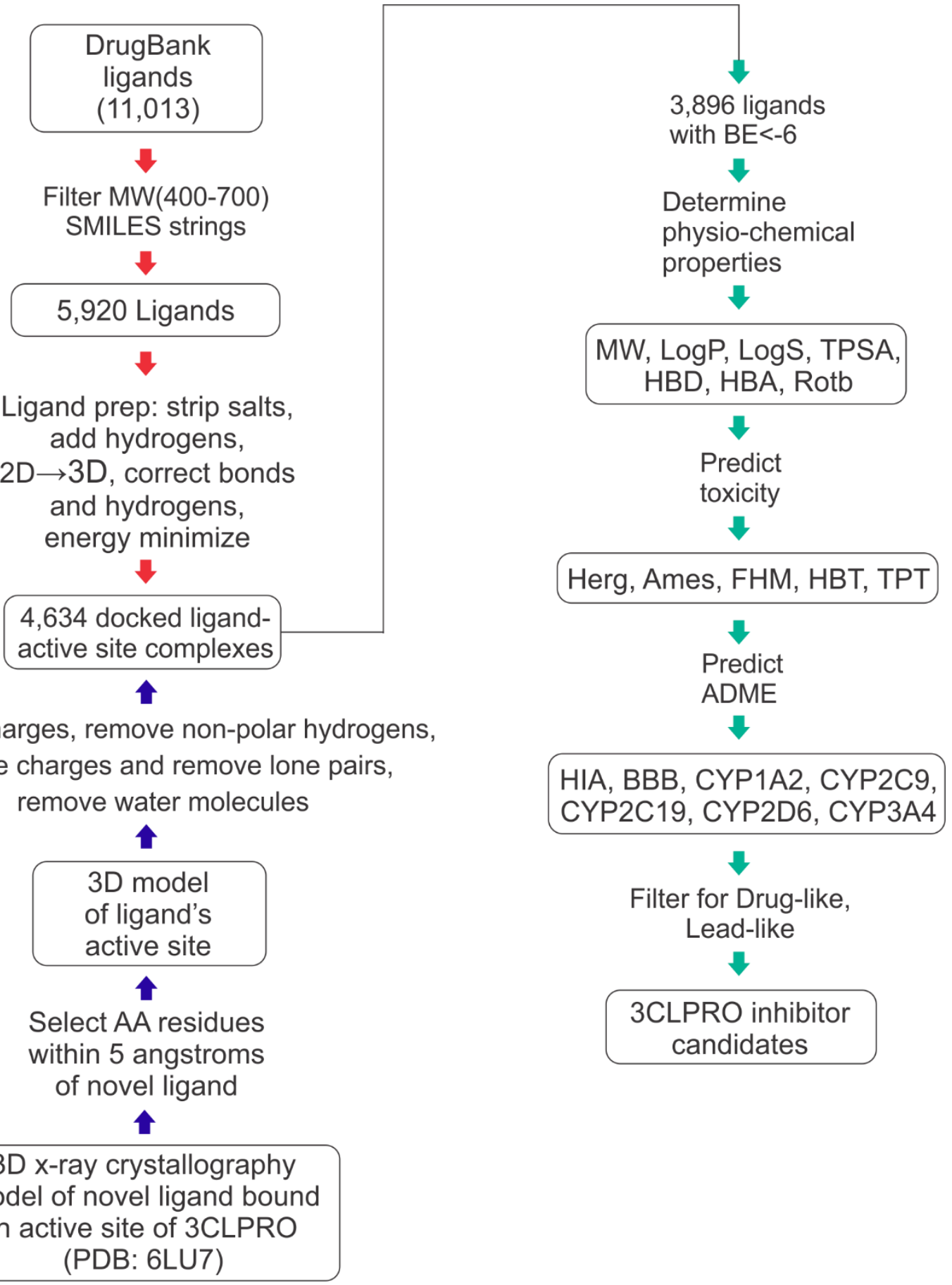

Figure 1. Workflow for ligand-active site docking and drug- and lead-like hit identification. 


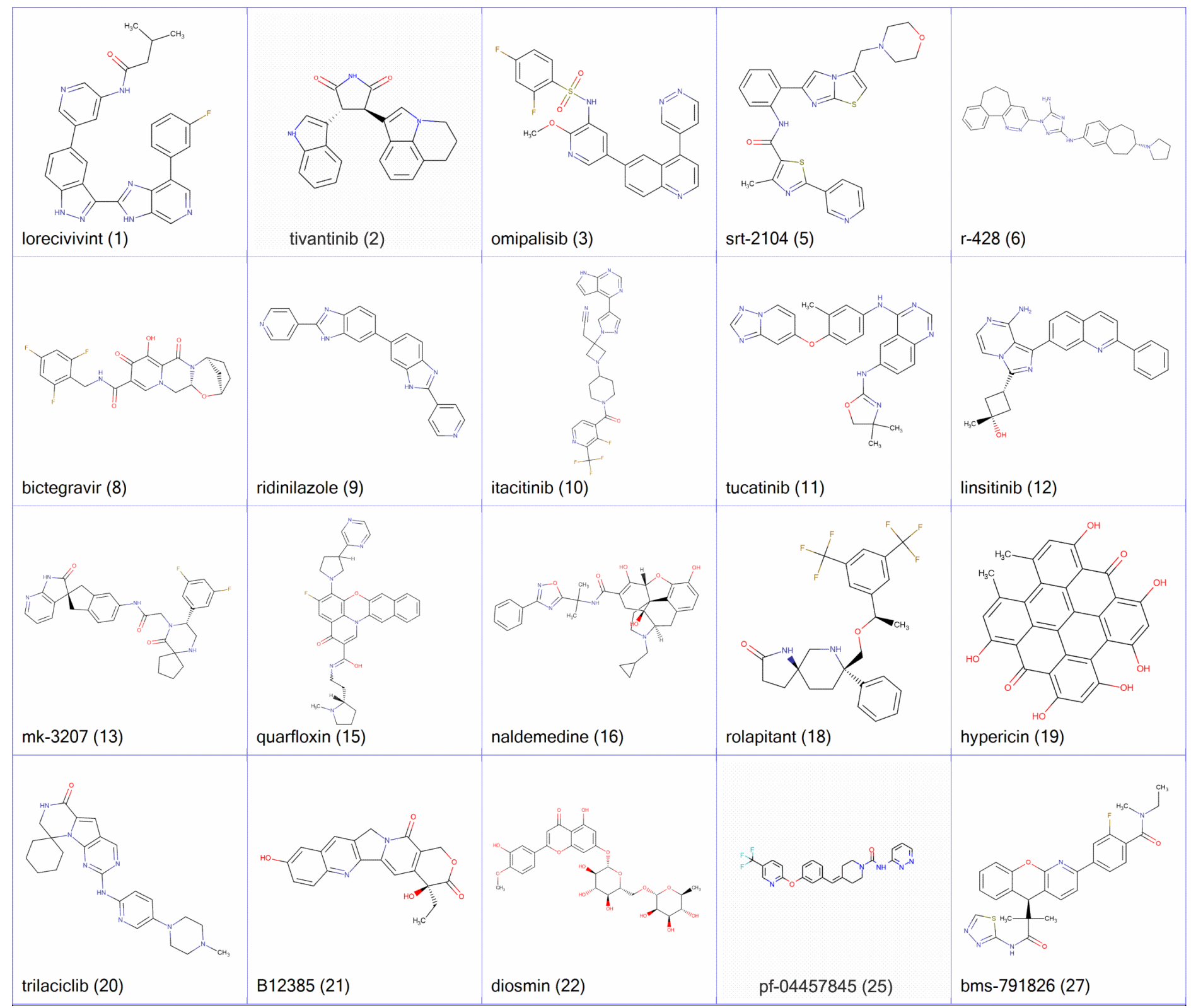

Figure 2. Top 20 investigational drugs and their ranks among 3,896 ligands with binding energy (BE) less than $-6 \mathrm{kcal} / \mathrm{mol}$. 


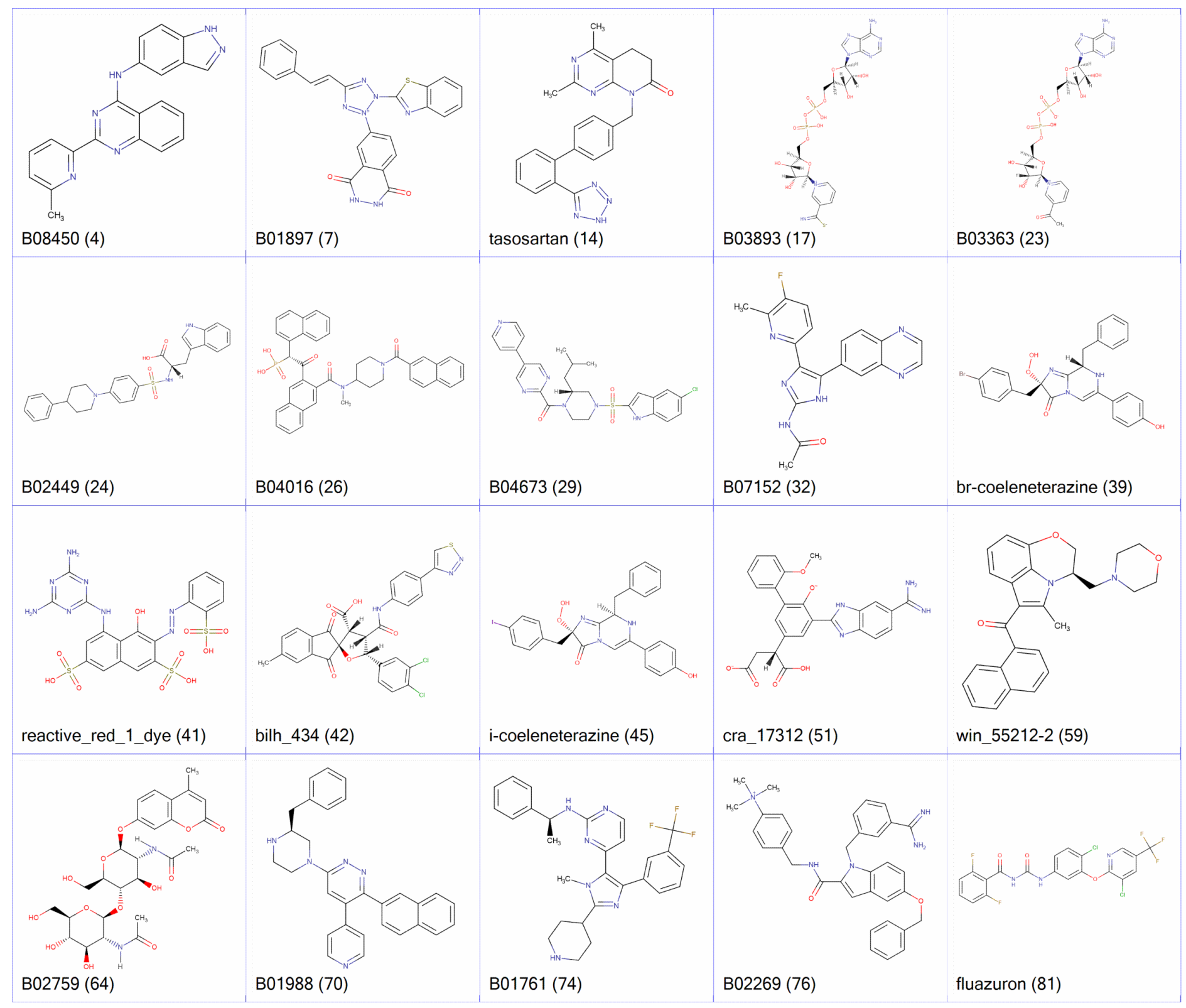

Figure 3. Top 20 experimental drugs and their ranks among 3,896 ligands with binding energy (BE) less than $6 \mathrm{kcal} / \mathrm{mol}$. 


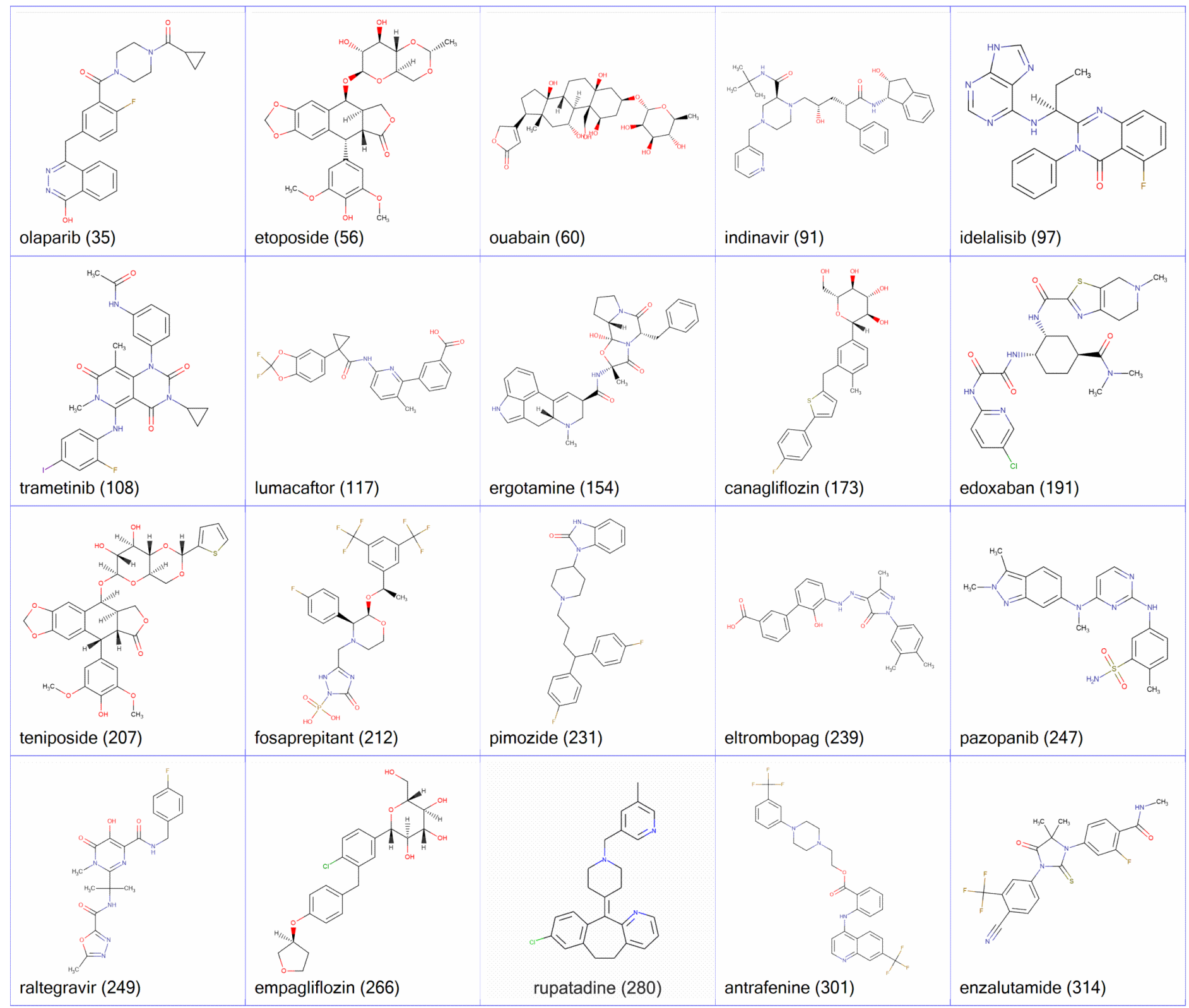

Figure 4. Top 20 approved drugs and their ranks among 3,896 drugs with binding energy (BE) less than -6 $\mathrm{kcal} / \mathrm{mol}$. 


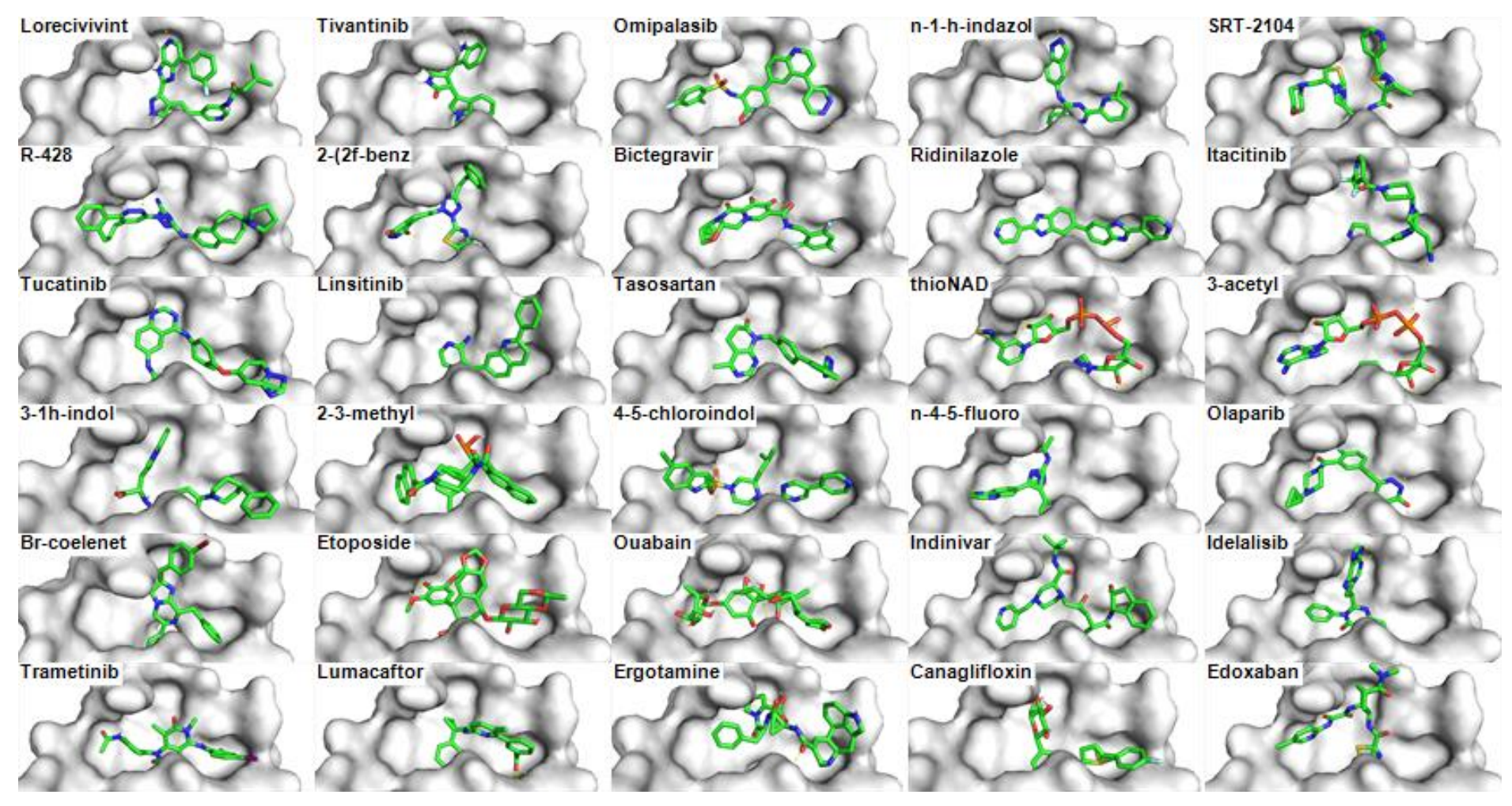

Figure 5. Putative binding poses of the Table 1 candidate hits. Each image shows the structure of the substrate binding pocket of the active site of the SARS-CoV-2 3CLpro protease (PDB ID: 6LU7). The white surface in each image represents the surface of the active site of 3CLpro that would be traced out by water molecules in contact with the protein at all possible positions. The inhibitors (ligands) are shown in molecular stick format. 

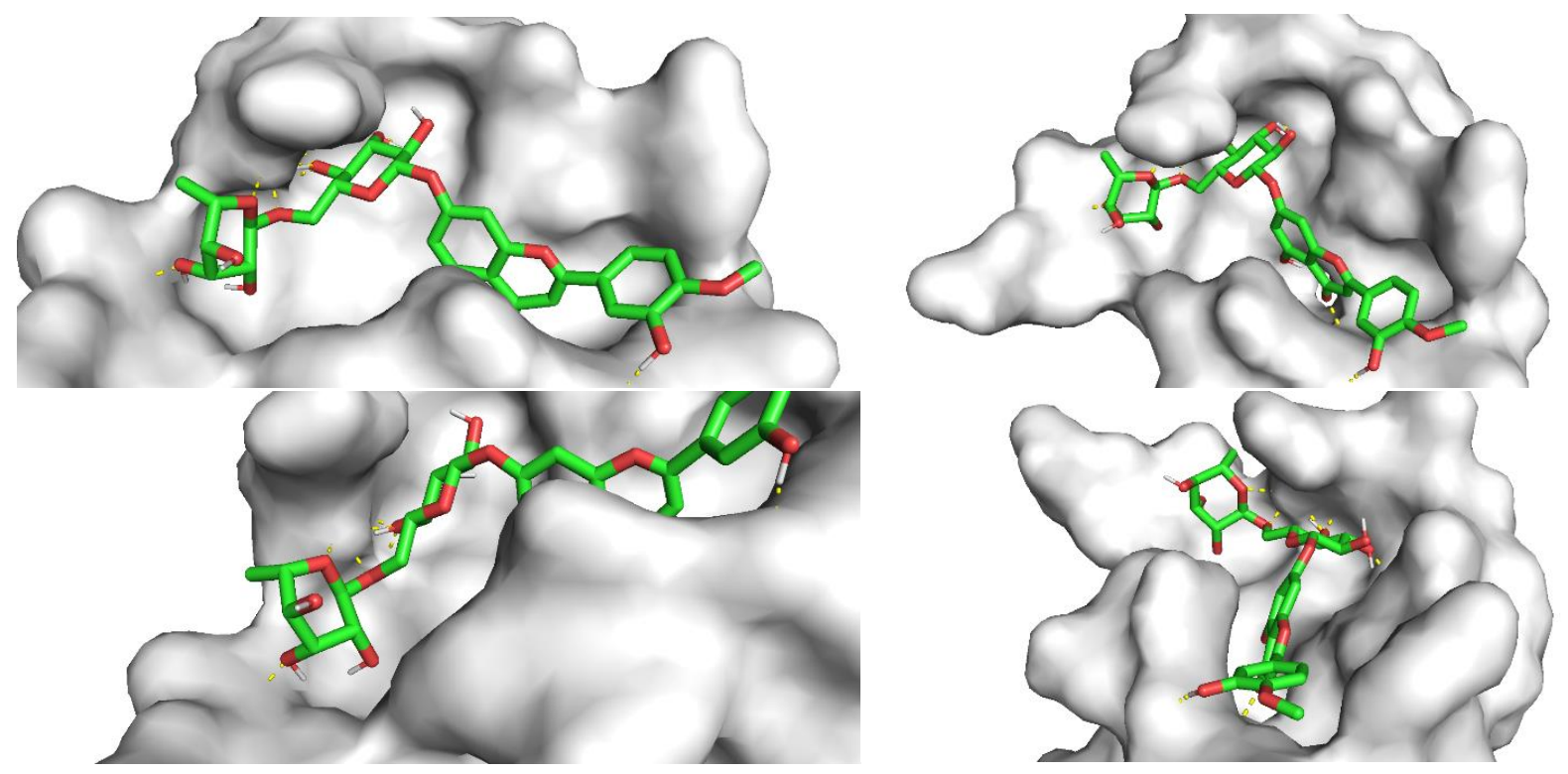

Figure 6. Putative docking pose for the natural supplement Diosmin (DrugBank ID B08995), shown in its energy-minimized state forming 8 hydrogen bonds and binding with the active site of SARS-Cov-2 3CLPro protease with a binding energy of $-8.8 \mathrm{kcal} / \mathrm{mol}$. 


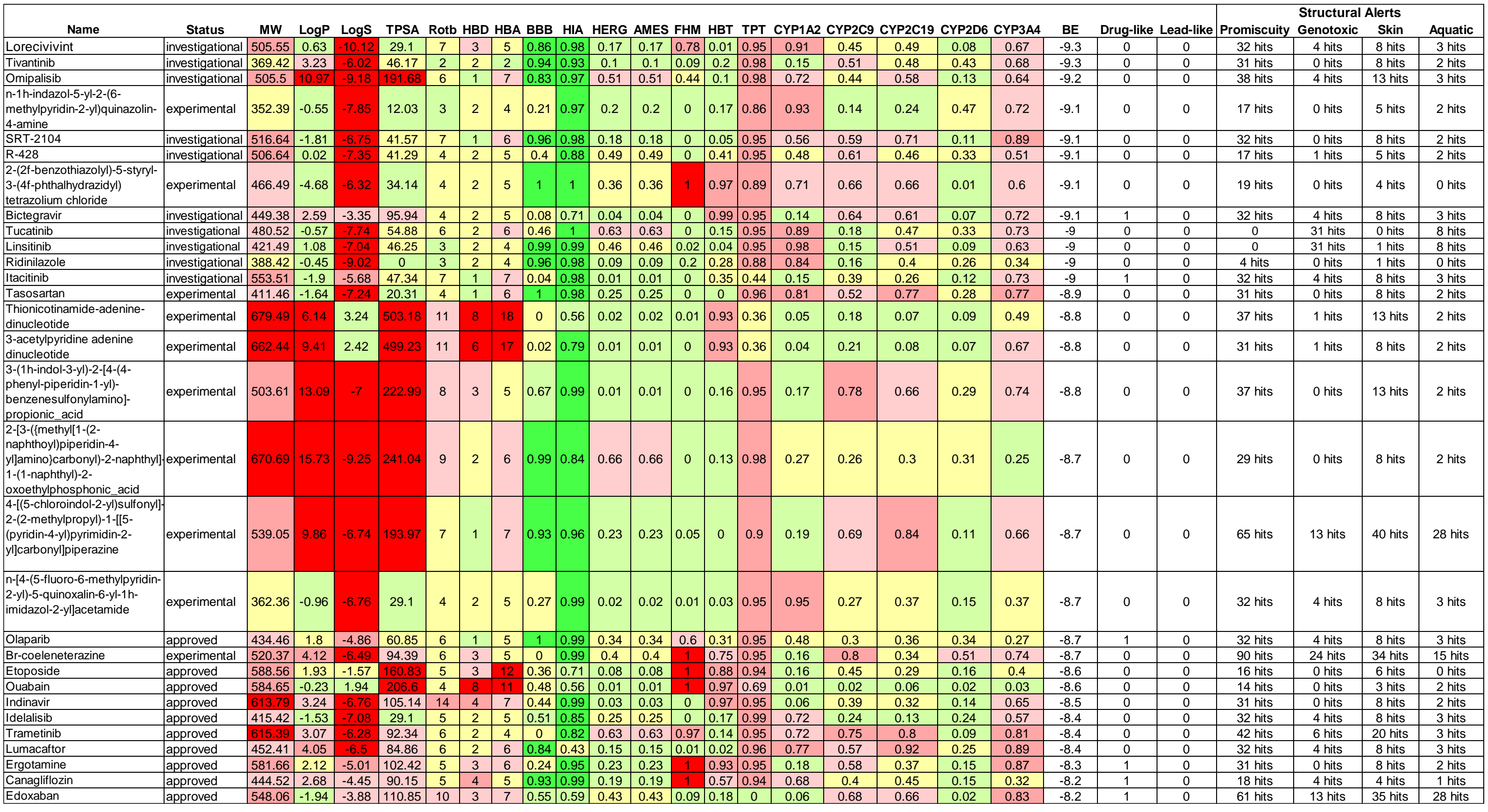




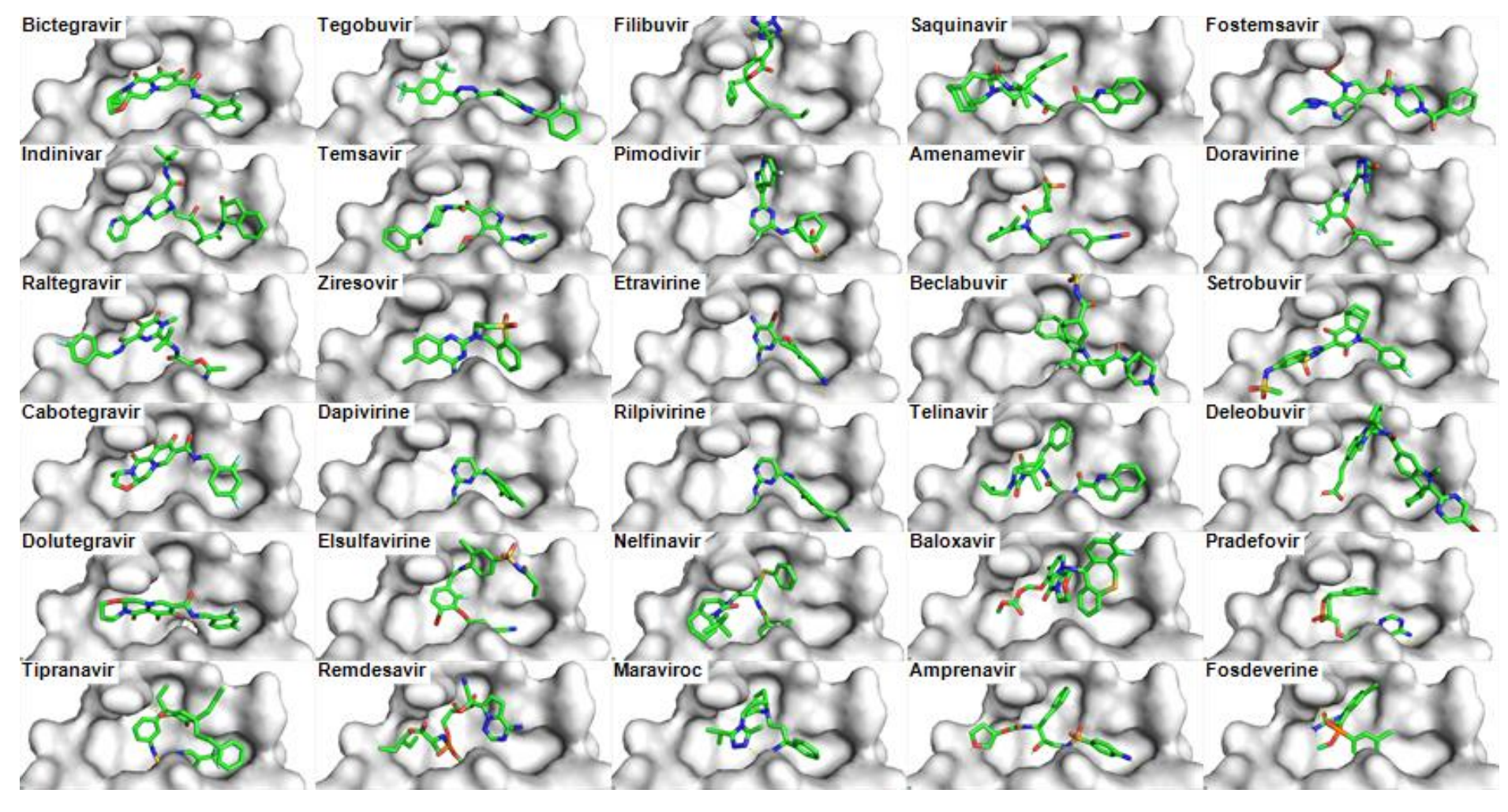

Figure 8. Putative binding poses of the 30 antivirals listed in Table 2. Each image shows the structure of the substrate binding pocket of the active site of the SARS-CoV-2 3CLpro protease (PDB ID: 6LU7). The white surface in each image represents the surface of the active site of 3CLpro that would be traced out by water molecules in contact with the protein at all possible positions. The antivirals are shown in molecular stick format. 